\title{
HOMOGENEIDAD Y FUNCIONALIDAD DE LA COSTA OCCIDENTAL DE HUELVA
}

\author{
José Manuel JURADO ALMONTE*
}

\section{INTRODUCCION}

En la actualidad, el tema de la comarca despierta bastante interés para diversas especialidades. Siendo una demarcación territorial mal definida física y humanamente, sin ningún poder institucional, ha pasado a tener una cierta importancia (Cataluña) como base para una planificación administrativa, económica y social; aparecen así las comarcas programáticas.

Uno de los problemas básicos en la comarcalización es el establecimiento de límites; cuestión en la que radica gran parte de la existencia de la comarca dejando de ser un ente abstracto. Por lo tanto, el objetivo principal del comarcalizador será encontrar una delimitación lo más cercana a la realidad y la tarea del geógrafo consiste en utilizar el máximo de criterios y llegar a una síntesis, por cuanto más bases de juicio se posea mayores serán las posibilidades de alcanzar dichos objetivos.

Dos tendencias principales comprenden la mayoría de los criterios a la hora de comarcalizar. Por un lado, aquéllas que definen las comarcas como áreas uniformes o espacios homogéneos (entorno físico, economía, demografía, etc.) y por contra, los que las consideran como áreas funcionales con sentido propio por las relaciones socio-económicas que en ellas se establecen con un núcleo polarizador. El espacio no es sólo el lugar donde se colocan los elementos geográficos sino que es el ámbito de interacción de aquéllos con resultados cambiantes en el tiempo (CANO, G.; 1984).

La provincia de Huelva es un ejemplo de multitud de divisiones comarcales debido a la proliferación de criterios con los que autores y organismos han dividido dicho espacio (MONTEAGUDO, J.; 1986). La indefinición de esta provincia y su falta de identidad específica parece constituir una realidad palpable desde los inicios de su configuración (1833), encontrándonos con una

* Becario de F.P.I. de «Análisis Geográfico Regional». Sevilla. 
clara desarticulación que llega hasta la actualidad (OJEDA RIVERA, J.; 1985). En este sentido, la comarca de la Costa, la más reducida y homogénea frente a las restantes, no se halla recogida de forma sintética en la mayoría de las comarcalizaciones; las cuales, parcialmente, conseguían una disgregación de su espacio. Es el objetivo de este capítulo reseñar su delimitación territorial, tomando como base criterios geográficos diversos y funcionales, con abundante información estadística y cartográfica que acompaña y completa el texto.

\section{ESPACIO HOMOGENEO}

Se conseguiría una comarcalización homogénea al estudiar primero variables geográficas por separado (población, explotación agraria, cultivos, industria, turismo, etc.) y, después, se superpondrían, globalizando, los elementos y obteniendo unos límites sintetizadores. La comarca homogénea se asimilaría así a comarca geográfica (CANO, G.; 1985); en ella se combinan los elementos físicos y humanos.

Se ha tomado como área de estudio para contrastar las principales variables geográficas el ámbito suroccidental de la provincia de Huelva, abierto al Océano Atlántico en un frente desde el río Guadiana al estuario Odiel-Tinto y hacia el norte, incluyéndose las primeras estribaciones montañosas del Andévalo.

a) Desde un punto de vista físico-natural comprobamos una diferenciación neta entre la Costa y el Andévalo; se trata del límite sur de la Iberia Silicea (HERNANDEZ PACHECO) que se orienta de noreste a sureste alcanzando el norte de los mismos municipios costeros (mapas n. ${ }^{\text {os }}$ I y II). De esta manera, el marco geográfico se caracteriza por tres unidades básicas, recogidas ya por Gonzalo Tarín (1886):

- Una estrecha banda litoral, de dominio cronológico muy reciente (Cuaternario) en la que domina los procesos de deposición y acumulación con una dinámica litoral muy potente, móvil e inestable que origina un singular paisaje geomorfológico de islas barreras, playas, dunas, marismas, acantilado fósil, etc. La interacción de la deriva litoral, las corrientes de marea y el viento y su conexión con la orientación de la costa, presencia de ríos y movimientos neotectónicos explican la configuración de esta zona (OJEDA ZUJAR, J.; 1988). Un cambio en las condiciones de este transporte sedimentario tendrá como consecuencia inmediata una transformación también en la línea costera. 


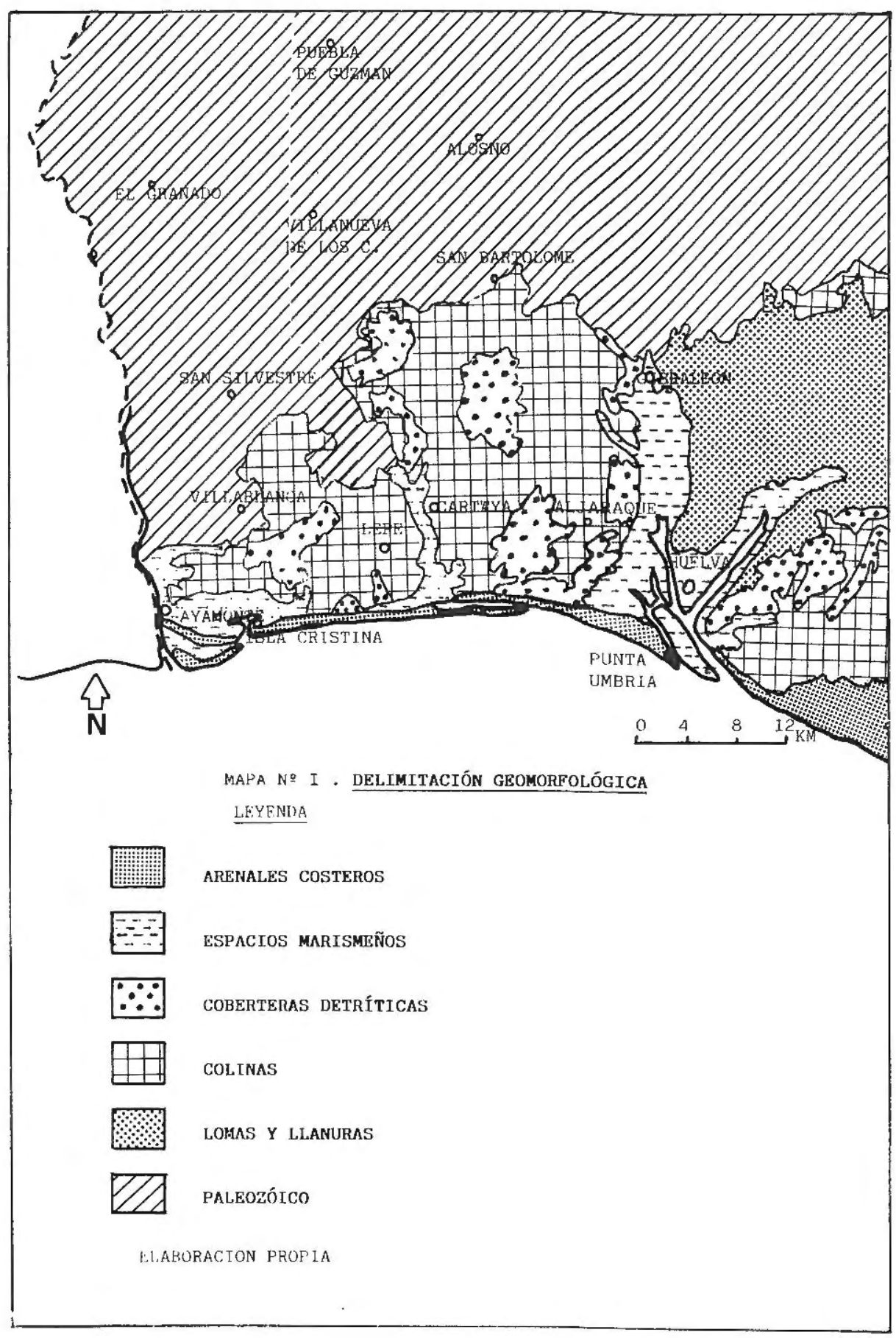




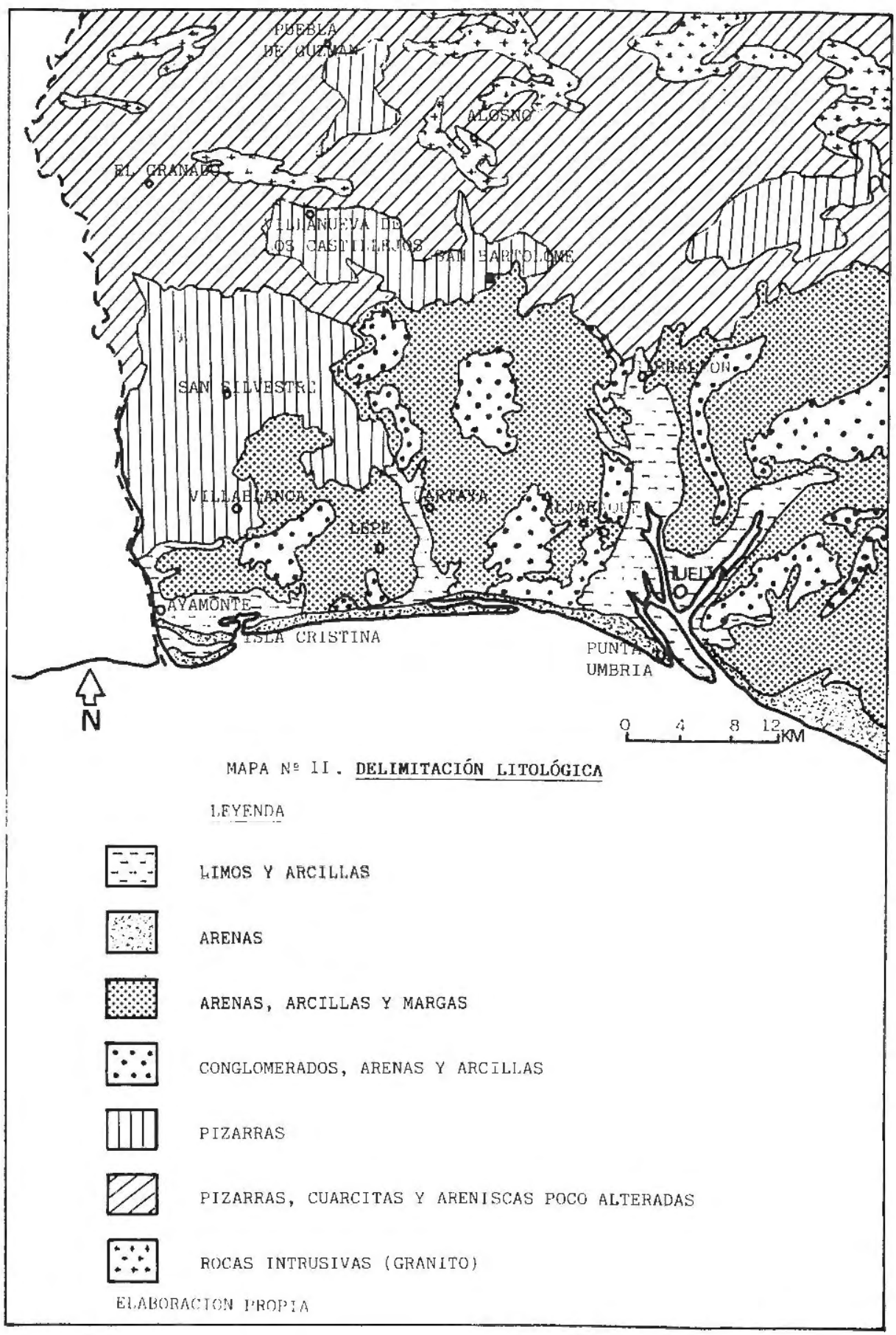


- Una franja de «campiña» agrícola con un sustrato geológico constituido por margas, calizas y arenas del Mioceno y Plioceno donde se han desarrollado formaciones edáficas que dependiendo de dicho sustrato van desde los suelos de tipo rojo a los de tipo calcimorfo de alta vocación agrícola. La topografía llana se rompe por pequeñas elevaciones del terreno («cabezos»).

- Dicha zona de transición separa el borde costero del zócalo paleozóico del Andévalo que se caracteriza por una topografía accidentada de rocas graníticas y metamórficas que originan suelos poco evolucionados (lítosols, rankers y regosoles) y pobres en nutrientes, aptos para el aprovechamiento forestal.

En cuanto a las formaciones vegetales naturales, pasamos en un corto recorrido espacial del encinar y matorral en las estribaciones de S. ${ }^{a}$ Morena a una vegetación azonal de marismas y arenales costeros. En el área de transición, el encinar y alcornocal se reducen actualmente a pequeños islotes, sustituidos por repoblaciones de pinos y eucaliptos.

En este espacio litoral, nos encontramos paisajes diversos de gran valor ambiental, ecológico y económico: playas, marismas, pinares, espacios agrícolas, que ofrecen una nota de singularidad frente a los espacios circundantes.

b) En el aspecto demográfico, la comarca de La Costa está compuesta por núcleos de carácter urbano en aumento poblacional durante todo el presente siglo, constituyéndose en la segunda zona de mayor crecimiento y densidad provincial, muy cerca de los niveles que alcanza el Area Periurbana de Huelva y, a diferencia del Andévalo y Sierra onubense (cuadro n. ${ }^{\circ}$ I y gráfico n. ${ }^{\circ} \mathrm{I}$ ). Excluyendo la capital provincial, del conjunto de siete municipios que superan los 10.000 hab. los tres primeros se hallan en este litoral. Nos referimos a: Ayamonte (16.775), Lepe (15.188) e Isla Cristina (14.954); otros dos se encuentran muy cerca de esta barrera: Cartaya (9.698) y Punta Umbría (9.491) (gráficos $\mathrm{n}^{\text {os }}$ II y III).

En el cuadro $n .^{\circ}$ II se comprueba las diferencias existentes entre los municipios litorales y los de su área circundante en lo que concierne a su evolución demográfica en diferentes intervalos de tiempo. Muestra los primeros un carácter claramente progresivo respecto a los pequeños y medianos núcleos del interior con tendencia muy regresiva (El Almendro, Alosno, Sanlúcar de Guadiana, San Silvestre, Villablanca, etc.). Las proyecciones demográficas ofrecen así mismo resultados positivos en los primeros en base al mantenimiento o ligera reducción de las tasas de crecimiento vegetativo y a saldos migratorios favorables; mientras que los segundos presentan tasas negativas aumentadas por el gradual envejecimiento de la población y descenso de natalidad, si bien 
GRAFICO N2I

EVOUDON DEMOCRAACA DE LOS ESPACOS COMARCALS DE LA PROVINOA DE HUELVA $N^{2}$ indices

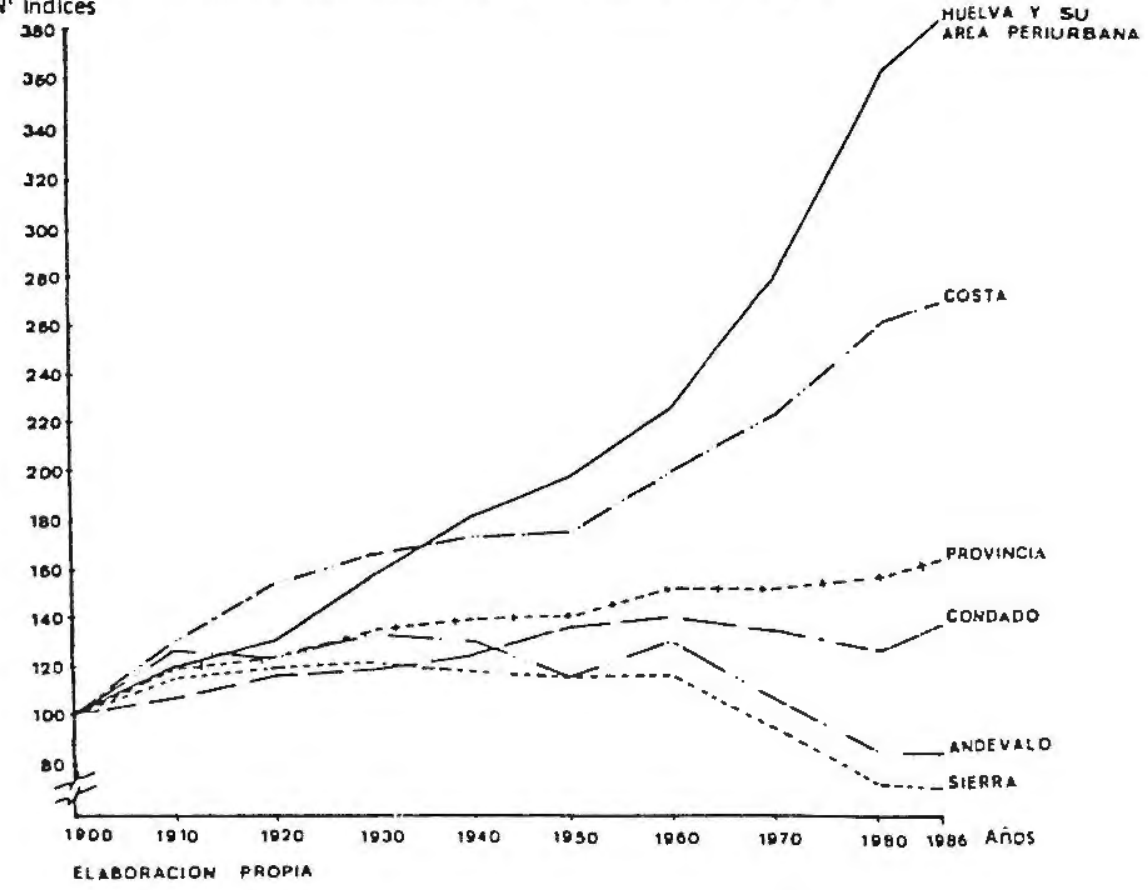

GRAFICO NNII

EVOLUCION HSTORICA EN NUMEROS ABSOLUTOS DE LA POBLA.TON DE I A COSTA OCCOENTAL OVUEENSE DE 1900 A 1986 $N$ : naoltantes (en mites)

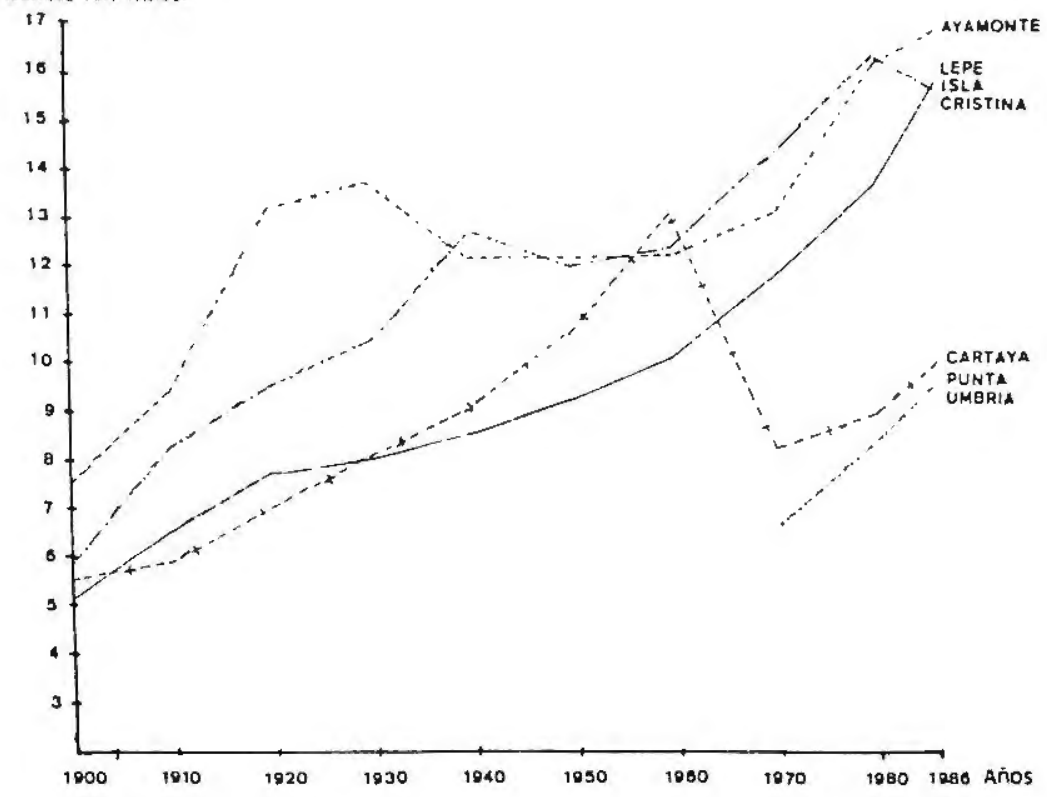


frenado por el cese del ritmo acelerado de la emigración. También se diferencian en cuanto a estructura de edad, tasas de actividad (mayores en los primeros), distribución de la actividad (predominio del sector agrícola y ausencia del sector pesquero en la periferia), densidad de población y potencial urbano (cuadro n. ${ }^{\circ}$ III). En este sentido, sólo Gibraleón y Aljaraque poseen unas estructuras demográficas similares a los municipios costeros.

\section{GRAFICO № III}

EVOLUCON HSTORICA EN NUAEROS NOCES DE LA PORACON DE LOS MUNCPIOS DE LA COSTA OCODENTAL ONUEENSE

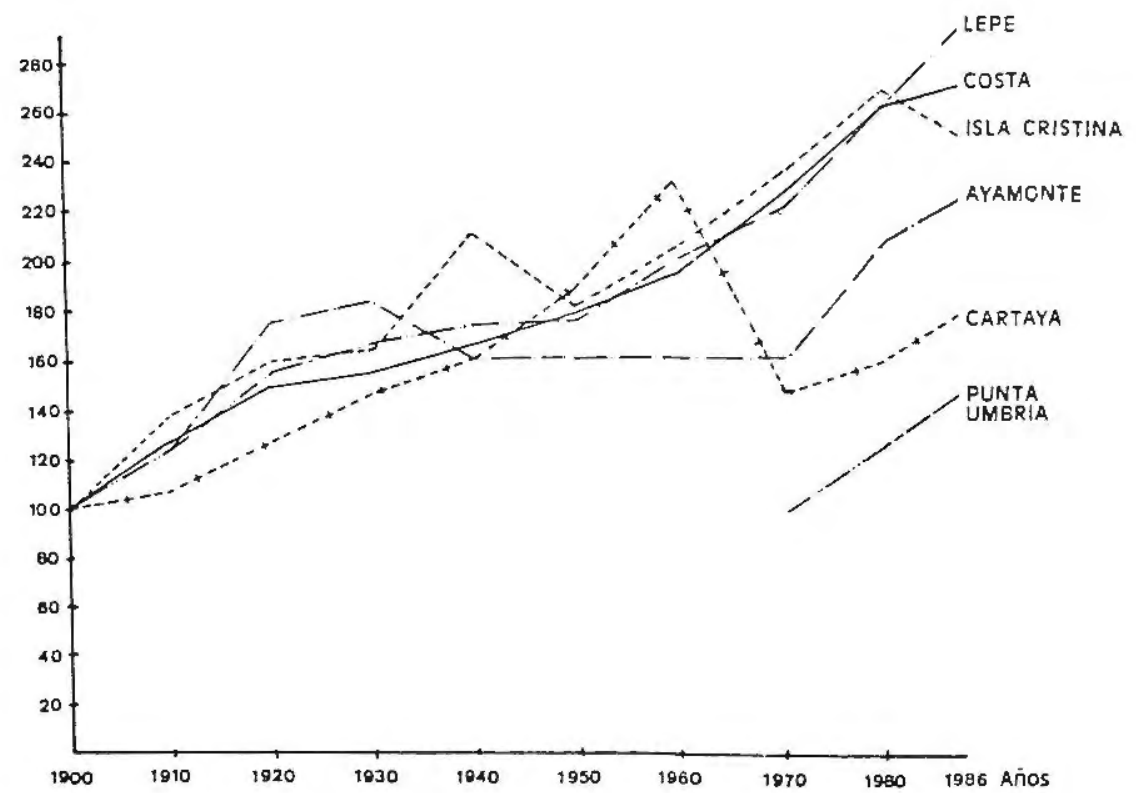

c) La característica más sobresaliente en el plano socioeconómico y territorial del litoral occidental onubense es la aparición y desarrollo desde la última década de la llamada Nueva Agricultura de Regadio. Junto a la transformación del espacio agrario se observa un cambio sustancial de la estructura económica y social agraria que incidirá en la economía general de la comarca. Se inicia dicho desarrollo en los municipios de Isla Cristina y Lepe, posteriormente en Ayamonte y Cartaya, y en la actualidad se orienta hacia Villablanca, Gibraleón y Aljaraque, ocupando la totalidad de la «campíña agrícola» (Plan de Regadíos del Chanza) (mapa n. ${ }^{\circ}$ III). Asistimos a una mutación de los sistemas de cultivos, que pasan de ser extensivos a intensivos, de secano a regadío 


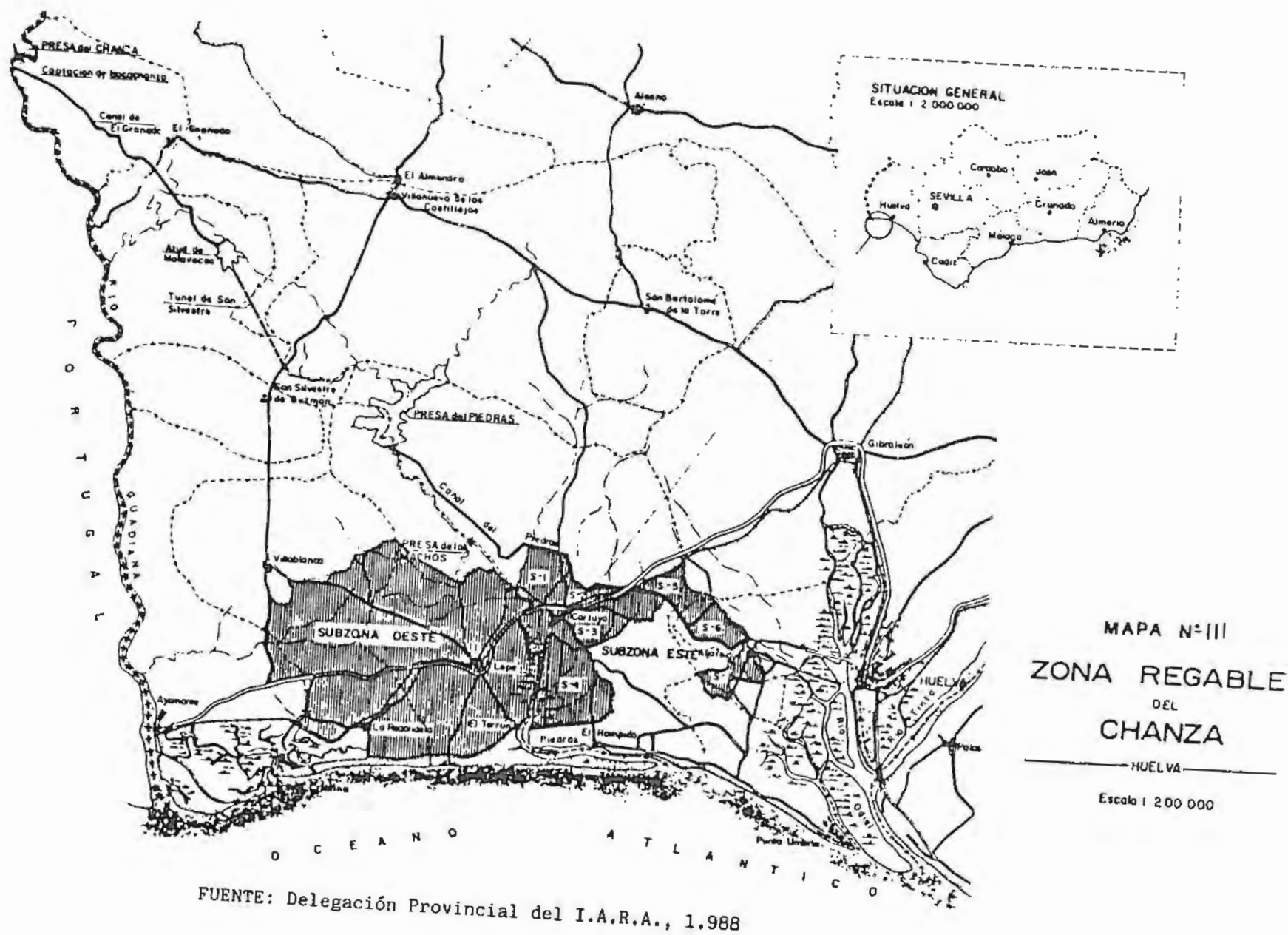


con nuevas técnicas y cultivos (fresón). Las modificaciones paisajísticas y territoriales se presenta en un descenso de la superficie forestal y la dedicada a cultivos tradicionales, y por contra, un aumento directamente proporcional de la superficie regable. Esta agricultura es realidad gracias a unos determinados factores físicos (clima, suelos y agua) y humanos (técnica, transporte y comercialización, disponibilidad de mano de obra agrícola y fuertes inversiones). Sus consecuencias son una mayor productividad, rentabilidad y beneficios en las rentas agrarias, desarrollo de actividades industriales y comerciales en torno a la agricultura (agribussines) y nuevos fenómenos sociales.

En suma, esta Nueva Agricultura se convierte en motor de expansión económica y constituye un nuevo marco diferenciador de esta comarca. Frente al predominio de la pequeña explotación agraria ( 0,1 a 10 has.) en el litoral (cuadro n. ${ }^{\circ}$ IV) con valores que superan en general el $75 \%$, los municipios septentrionales presentan una mayor concentración en la mediana y gran explotación. Por otra parte, en cuanto a la ocupación de la superficie agrícola (cuadro n. ${ }^{\circ} \mathrm{V}$ ), las diferencias también son claras: el litoral ofrece mayor ocupación agrícola, mientras que el interior se caracteriza por una agricultura tradicional extensiva (trilogía con barbecho), ausencia del regadío y elevada ocupación del espacio forestal.

d) El aspecto más significativo de los pueblos de la Costa es su dedicación a la vida del mar, influendo históricamente en la formación de una idiosincracia común en base a su dependencia. Para ello contaba con las ventajas naturales que les daba la existencia de rías-estuarios muy favorables para la instalación de pequeños puertos en sus márgenes (Ayamonte, Isla Cristina, El Terrón, El Rompido y Punta Umbría). Este sector pesquero tiene escasa incidencia en los municipios con menor contacto marítimo (Aljaraque, Gibraleón y Villablanca) y nula en el resto.

Al igual que en la agricultura, coexisten en este caso una pesca de bajura o artesanal y una pesca de altura. Predomina la primera en estas localidades, al abrigo de sus rías; la segunda se sitúa en el puerto de Huelva, cuya tripulación procede en gran parte de dichos núcleos. En la actualidad, a pesar de su discutida crisis estructural, el sector sigue siendo importante en la economía local del litoral, ofreciendo nuevas expectativas que se centran en la acuicultura (marismas) y actividades en torno a la pesca (astilleros, industrias conserveras y congelados).

Los municipios costeros presentan un sector industrial de cierta significación y diversidad donde se encuadran industrias tradieionales, ligadas a la pesca (Ayamonte e Isla Cristina), con otras nuevas, en torno a la transformación y comercialización de productos agroalimetnarios (agroindustrias) en Lepe y Cartaya; las industrias congeladoras, talleres mecánicos y madederos y las relacionadas con la construcción completan el panorama. El carácter familiar de 


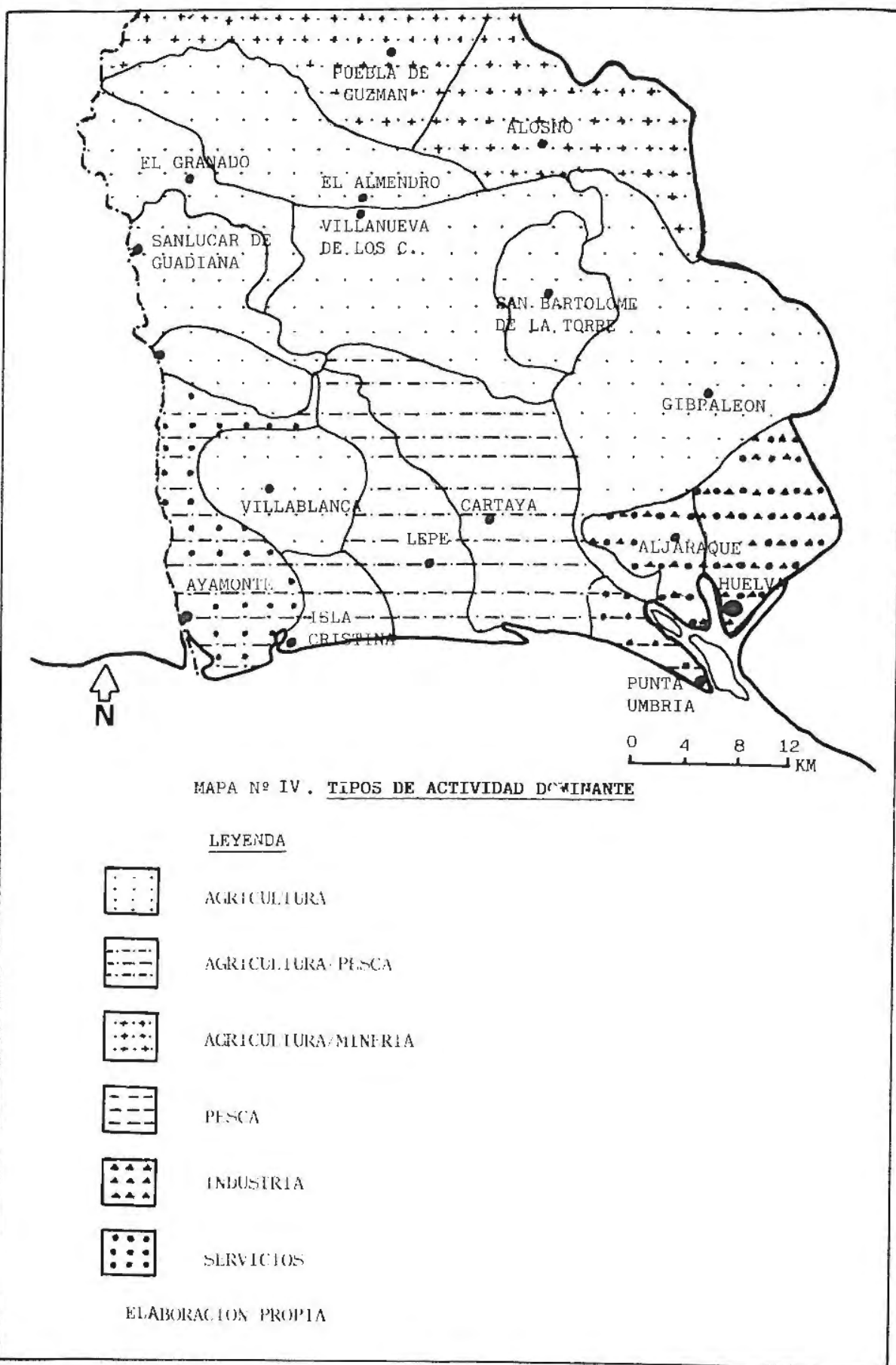

[10] 
estas industrias, con escasos recursos económicos e instalaciones pequeñas, ha variado en los últimos años ampliando su potencial y generando mayor empleo con grandes posibilidades de expansión y sin apenas incidencia en el medio ambiente.

El comercio representa una actividad complementaria de importancia, especialmente en Ayamonte e Isla Cristina que juegan el papel de centros intermedios de servicios a pequeñas poblaciones del interior (Villablanca, La Redondela y San Silvestre de Guzmán). En base a su potencial demográfico Lepe, Cartaya y Punta Umbría se convierten en núcleos de nivel medio, para su propio servicio. En el cuadro n. ${ }^{\circ}$ VI se muestra la situación de las actividades comerciales e industriales donde se resalta las diferencias existentes entre las poblaciones litorales y las situadas en su periferia.

La actividad turística alcanza una importancia creciente, suponiendo una alternativa socio-económica que hasta el momento sólo afecta directamente a los municipios costeros. A pesar de ser un espacio con elevado potencial turístico (playa-clima) no se puede considerar en la actualidad como un área altamente desarrollada en la industria del ocio; caracterizándose por ser un turismo de playa, de marcado carácter estacional y bajo nivel de equipamientos y servicios. Su aportación al desarrollo de la zona es muy inferior al deseado, consistente en la elevación de la renta y generación de empleo estacional en el sector comercial y servicios, representa un mercado de productos primarios e influye positivamente en el sector inmobiliario. La baja ocupación actual de este litoral permite, sin duda (FOURNEAU, F., 1983) un nuevo desarrollo turístico bajo una política de ordenación con menos excesos de gigantismo, que promueva el aumento del nivel de vida de sus habitantes y salvaguardando los paisajes naturales que se convierten en recursos de atracción.

\section{AMBITO FUNCIONAL GENERAL DE LA PROVINCIA DE HUELVA}

Los fenómenos más comunes en las nuevas relaciones Ciudad-Campo son la concentración económica y demográfica en la ciudad, un aumento de los desplazamientos y de los intercambios comerciales, financieros, económcos, culturales, etc. Este entramado de conexiones entre la ciudad y su entorno genera una vertebración del espacio que ha dado en llamarse espacio funcional (CANO, G.; 1985). Otros elementos que influyen en dicha determinación son la movilidad trabajo-residencia, localización industrial, inmigración; aunque, entre ellos destacan los fenómenos de intercambios comerciales (MARQUEZ, J.; 1989), en el doble sentido: CENTRO-PERIFERIA. 
Mapa V

COMARCAS HOMOGENEAS (A.I.S.S.)

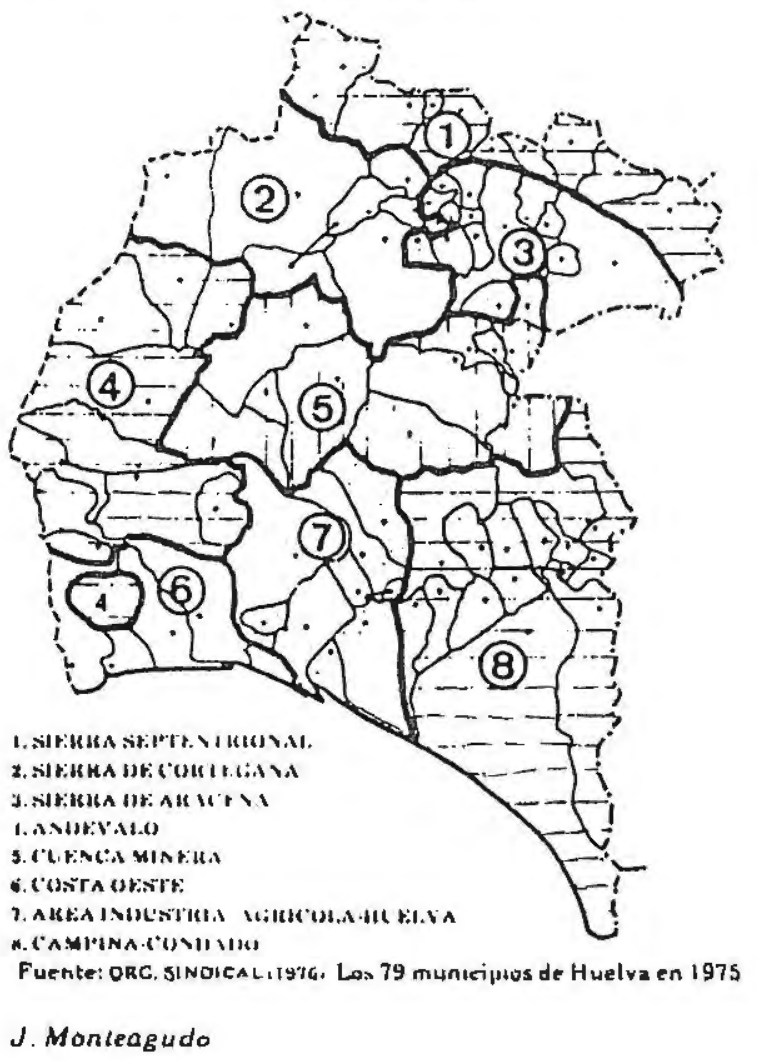

EL ENTORNO AGROINDUSTRIAL DE HUELVA

Y LA COMARCALIZACION PROVINCIAL

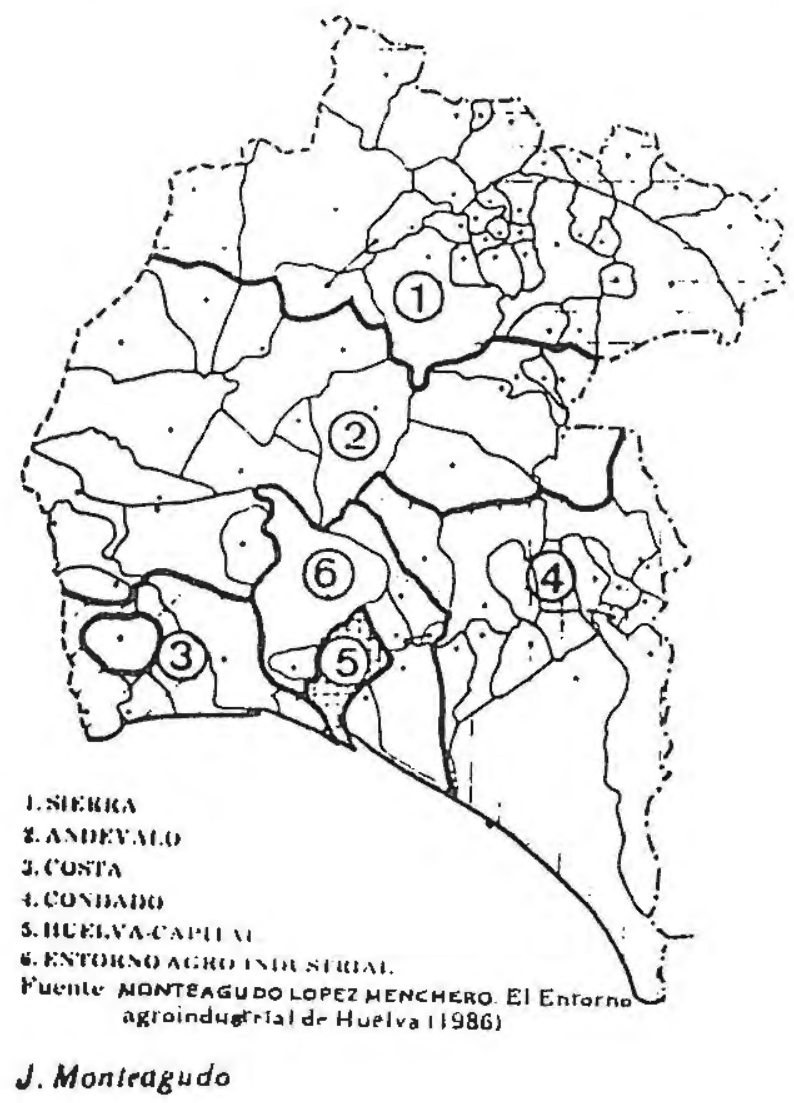


El Atlas Comercial de España elaborado por las Cámaras Oficiales de Comercio, Industria y Navegación (1963), fue adoptado por BANESTO para llevar a cabo su Anuario del Mercado Español. El espacio nacional queda dividido en áreas y subáreas de primera y segunda categoría; englobándose el centro del subárea por el de área, de forma jerárquica. De esta manera, la provincia de Huelva se divide en tres áreas: Huelva, Sevilla y Ayamonte. Esta última es la más pequeña, comprendiendo sólo a tres municipios: Ayamonte, Villablanca y San Silvestre de Guzmán (mapa n. ${ }^{\circ}$ VII).

La delimitación de dichas áreas se efectúa en base a encuestas sobre el abastecimiento de determinados servicios en los municipos y tomando las cuotas de mercado. Evidentemente, la realidad socio-económica ha cambiado considerablemente en el contexto litoral y regional respecto a la década de los sesenta. Así los núcleos de Isla Cristina, Lepe, Cartaya y Punta Umbría poseen tasas importantes en equipamientos y servicios.

Huelva-capital extiende su influencia en mayor o menor medida a todo el ámbito provincial al acumular las delegaciones ministeriales, autonómicas y otras instituciones públicas. Además, se constituye en el principal centro comercial e industrial a distancia de los restantes. Conforme nos acercamos a dicho centro, mayor es la intensidad en las relaciones. Tomando el factor frecuencia de transporte y accesibilidad, las relaciones más potentes se producen en un área con isocronas de 15 minutos (cuadro n. ${ }^{\circ} \mathrm{VIII}$ ). Incluiría las poblaciones de Gibraleón, Aljaraque, Palos de la Frontera, San Juan del Puerto y, en menor grado, Moguer y Punta Umbría.

Otro factor para determinar las áreas de influencias, relacionado con la accesibilidad, es el análisis de la movilidad trabajo-residencia. En este sentido, Huelva y su complejo industrial se constituye en lugar de trabajo de personas no residentes en ella sino en núcleos cercanos de su entorno (cuadro n. ${ }^{\circ}$ IX). Este fenómeno repercutirá en una estructura demográfica y económica peculiar, caracterizada por el peso del sector servicios, industrial y construcción que, en gran parte, no ejercen en sus lugares de residencia. De esta manera, Aljaraque y Gibraleón cumplen, en parte, un papel de ciudades dormitorios. Por contra, la vinculación de Ayamonte, Isla Cristina y Lepe es escasa, mientras aumenta en Punta Umbría y Cartaya.

En 1986 la Dirección General de Ordenación del Territorio de la Consejería de Política Territorial crea una nueva comarcalización del espacio andaluz, basado en el sistema de ciudades y sus ámbitos funcionales. Sus objetivos principales son las de servir de instrumento de racionalización para la gestión de las administraciones públicas, en un intento de crear fórmulas encamiandas a lograr la máxima funcionalidad de las inversiones públicas (MONTANER, J.; 1986). De esta manera, se combinan la delimitación funcional con el objetivo programático. En este estudio, se define área de influencia como el ámbito 
AREAS COMERCIALES

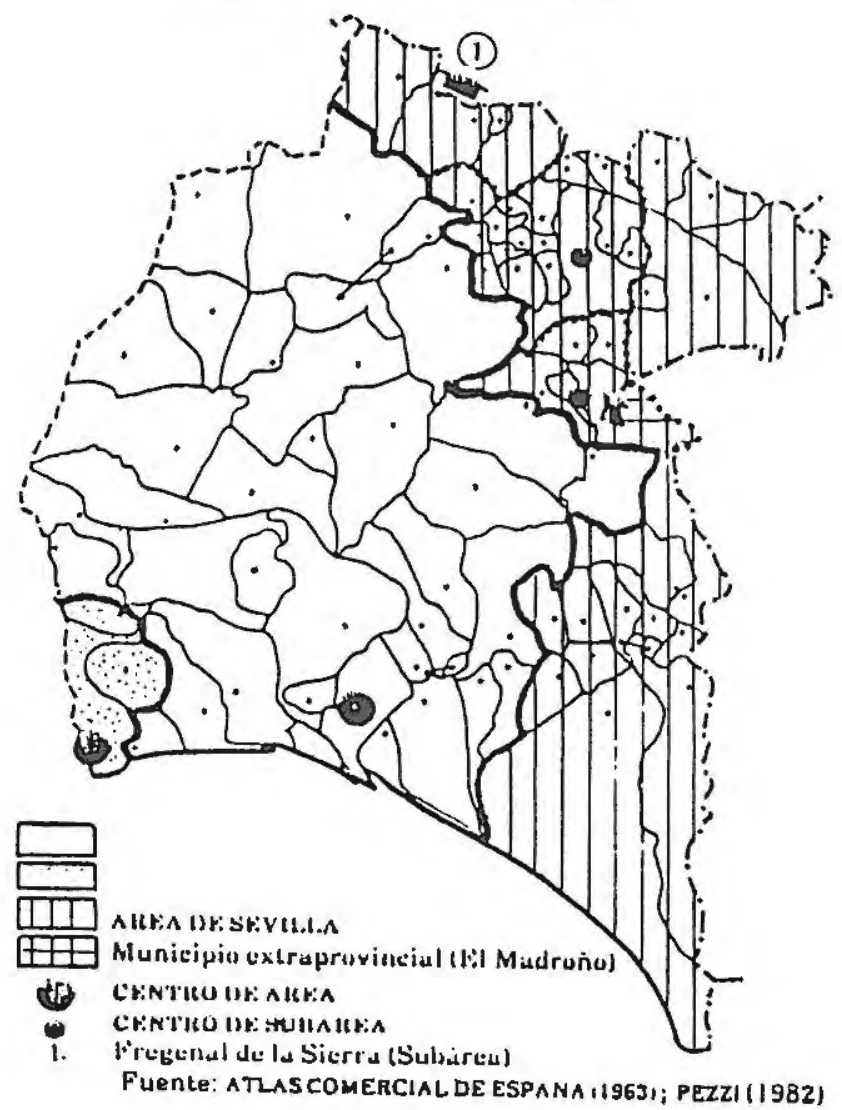

SISTEMA DE CIUDADES.

JUNTA DE ANDALUCIA

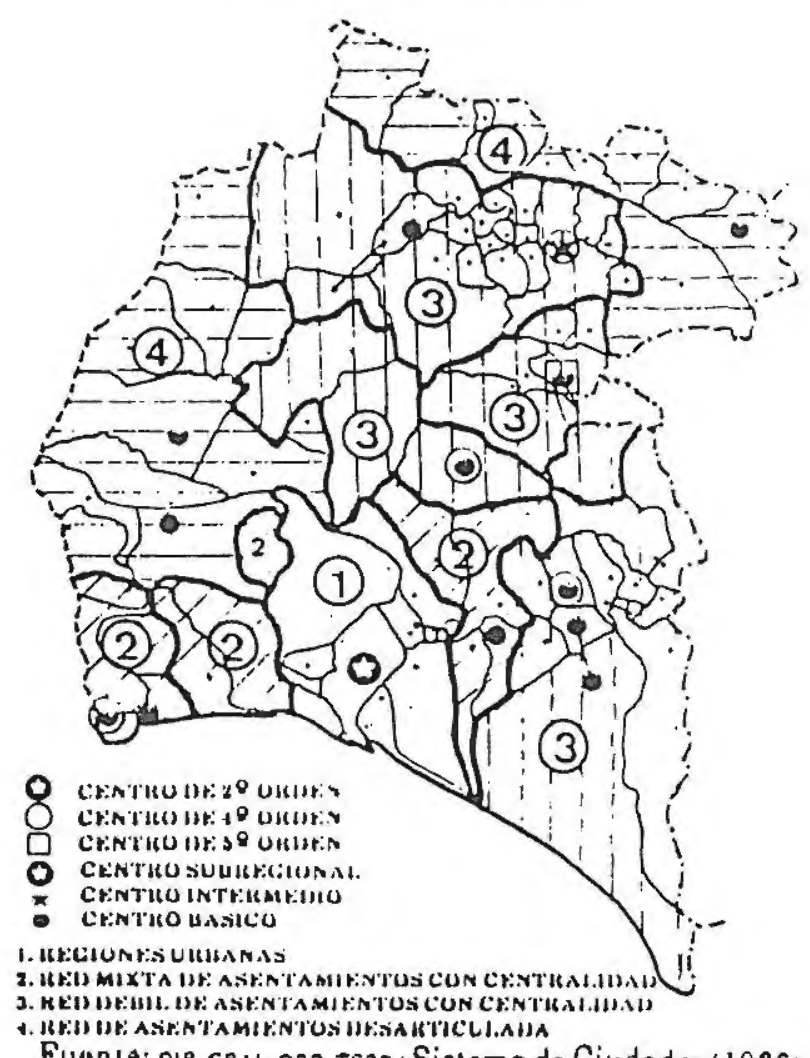


territorial que cubre determinados núcleos para la provisión de bienes y servicios. Las áreas de influencia de cada núcleo se determinan por las funciones públicas y privadas que poseen, jugando como factores la accesibilidad y los umbrales de compra.

En el marco del sistema de ciudades de Andalucía, la comarca de Ayamonte-Isla Cristina (mapa n. ${ }^{\circ}$ VIII) es encuadrada como Red Mixta con asentamientos con centralidad, mientras queda englobado en el primer orden como Región Urbana el Area Periurbana de Huelva, comprendiendo como municipios de fuerte interrelación funcional a Gibraleón, Aljaraque, Palos de la Frontera, Moguer, San Juan del Puerto, Punta Umbría y Trigueros. En cuanto a los centros, Huelva-capital pertenece al $2 .^{\circ}$ orden, ciudad con ámbito de influencia subregional, y Ayamonte-Isla Cristina al cuarto, núcleos con clara centralidad y débil potencial funcional. Por contra, las comarcas de Villanueva de los Castillejos y Puebla de Guzmán presentan una red de asentamientos desarticulada y sus dos centros básicos son núcleos de débil centralidad y potencialidad funcional.

\section{AMBITO FUNCIONAL DE LA COSTA OCCIDENTAL DE HUELVA}

El nivel de equipamiento de un núcleo de población, fundamental para determinar su radio de influencia, tiene una fuerte relación con la actividad comercial que desarrolla; y para ello, dos serán las principales variables a seguir: las licencias comerciales y la cuota de mercado. Esta última se define como indicador de «la cantidad de productos o servicios que, teóricamente y en igualdad de condiciones pueden absorver las áreas territoriales» (BANESTO, 1985), siendo un valor en el que intervienen diversas variables de mercado de carácter económico y social. El cuadro $\mathrm{n} \cdot{ }^{\circ} \mathrm{X}$ nos permite establecer las siguientes distribuciones:

a) El predominio de Huelva-capital, centro administrativo, comercial e industrial de la provincia.

b) En segundo lugar, la existencia de un grupo de núcleos con un nivel de equipamiento elevado en consonancia con su peso poblacional y económico; nos referimos a Ayamonte, Isla Cristina y Lepe.

c) Un tercer grupo de menor equipamiento global aunque con tasas elevadas: Punta Umbría, Cartaya y Gibraleón.

d) Núcleos con un nivel de equipamiento bajo: Aljaraque, Alosno, Puebla de Guzmán, Villanueva de los Castillejos y San Bartolomé de La Torre.

e) Poblaciones con débiles centros comerciales y de servicios: Villablanca, El Almendro, San Silvestre de Guzmán y Sanlúcar de Guadiana. 
Por otra parte, para completar el análisis del ámbito de influencia de La Costa se ha utilizado como metodología básica la encuesta, realizada a los distintos Ayuntamientos del área en estudio (FERIA, J.M. y SISTEMA DE CIUDADES, 1986). Permitiría medir el nivel de servicios y equipamientos que cada núcleo posee y la movilidad de personas que se genera para adquirirlos; con ello se podría determinar las áreas desarrolladas en servicios y, consiguientemente, trazar sus espacios de influencia.

Con el mismo ámbito territorial trazado desde un principio, se han barajado veinticinco variables de servicios y equipamientos diversos, solicitando respuesta sobre su presencia en el mismo núcleo y movimiento de la población para conseguirlos como segunda alternativa o por obligación dada su posible no existencia. Abarcan un conjunto desde los propiamente comerciales (confecciones, electrodomésticos, muebles, etc.) a profesionales (dentistas, abogados, arquitectos, etc.), como a equipamientos urbanos (Instituto de B.U.P. y F.P., asilos, matadero, etc.) (cuadros n. ${ }^{\circ}$ XI, XII, XIII y XIV). Una última vriable es la movilidad laboral en base a los desplazamientos diarios desde los lugares de residencia a los de trabajo. En dicho cuadro ( $n .^{\circ} \mathrm{XV}$ ), se facilita información sobre la importancia del contingente y las actividades preferentes que desarrollan.

La investigación realizada en base a la encuesta corrobora en parte las conclusiones del cuadro n. ${ }^{\circ} \mathrm{X}$ sobre el nivel de equipamiento y cuota de mercado aunque posibilita mayores matizaciones:

a) Los núcleos de Ayamonte, Isla Cristina y Lepe, y en menor medida, Cartaya y Punta Umbría, poseen equipamientos comerciales y servicios variados permitiendo que su población los adquiera mayoritariamente in situ. No obstante, Huelva representa un centro de atracción de otros tipos de servicios (administrativos y sanitarios) inexistentes en aquéllos y, además, constituye una segunda alternativa por su mayor diversidad y volumen (hipermercados y grandes almacenes); extendiendo, sobre tọdo, su influencia a los núcleos más próximos, con menor dotación y mayor movilidad laboral: Punta Umbría y Cartaya.

b) Gibraleón y Aljaraque constituyen núcleos medianamente equipados, con fuertes vinculaciones con la capital en lo que se refiere a movilidad laboral (industria, servicios y construcción), convirtiéndose, en parte, en ciudades dormitorios (Barriada de Bellavista en Aljaraque). Dada su cercanía y alta accesibilidad se convierte también en centro de servicios comerciales y profesionales. Dichas funciones han posibilitado que se las incluya dentro del Area Periurbana de Huelva (SISTEMA DE CIUDADES, 1986) con estructuras demográficas y económicas diferentes a los municipios propiamente costeros. 
c) Villablanca y San Silvestre de Guzmán, localidades con bajo nivel de equipamientos, tienen su centro de servicios, tradicionalmente, en Ayamonte, conformando en conjunto este Area Comercial (BANESTO, 1963). Más recientemente, ambas poblaciones se abren hacia Huelva y Lepe debido a las mejoras de las comunicaciones por carretera (construcción final del tramo Lepe-Villablanca de $14 \mathrm{kms}$.). Los núcleos costeros son foco de atracción para una importante población activa que se traslada diariamente para ocupaciones relacionadas con la agricultura y la construcción.

d) El resto, forman un conjunto de núcleos (Andévalo suroccidental que tiene en Huelva su principal centro gracias a su capacidad de atracción, y como centros básicos a Puebla de Guzmán y Villanueva de los Castillejos. A pesar de su cercanía, sus relaciones con La Costa son escasas, más que como centro de servicios en destinataria de mano de obra diaria o temporal.

Pese a no encontrar una homogeneidad estricta en cada uno de los municipos de población, sí podemos trazar un ámbito funcional con garantías. Cuando nos referimos a la comarca de LA COSTA, distinguiremos:

a) Un centro, caracterizado por su fuerte desarrollo económico y con un nivel de equipamientos comerciales, profesionales y urbano autosuficiente, constituyéndose en los últimos años en importante area de atracción laboral de ámbitos incluso extraprovinciales (Nueva Agricultura). Comprendería los municipios de Ayamonte, Isla Cristina, Lepe, Cartaya y Punta Umbría (ésta última recogida en el Sistema de Ciudades dentro del ámbito de Huelva).

b) Una periferia, que si bien puede hacerse más extensible, teniendo en cuenta la movilidad laboral, se reduce a Villablanca y, en menor grado, San Silvestre de Guzmán. Ambos municipos se benefician del desarrollo económico del litoral en cuanto a ocupación laobral y por la ampliación del regadío en sus términos (Villablanca). Los municipios de Gibraleón y Aljaraque quedan englobados por sus relaciones funcionales en el Area Periurbana de Huelva a pesar de poseer otras semejanzas de tipo físico y humano con los propiamente litorales.

Observamos un claro paralelismo de La Costa en cuanto a sus delimitaciones homogéneas y funcionales. Sin embargo, no existe una conciencia comarcal definida entre sus habitantes al estar constituida por núcleos urbanos de fuerte carácter individual, pero con intensas relaciones sociales y económicas entre sí: Ayamonte, Isla Cristina, Lepe, Cartaya y Punta Umbría. 


\begin{tabular}{|c|c|c|c|c|c|c|c|c|c|c|c|c|}
\hline \multirow{2}{*}{ Comarcas } & \multirow{2}{*}{$\begin{array}{l}\text { Núm. } \\
\text { Munic. }\end{array}$} & \multirow{2}{*}{ Indicadores } & \multicolumn{10}{|c|}{ Años } \\
\hline & & & 1900 & 1910 & 1920 & 1930 & 1940 & 1950 & 1960 & 1970 & 1980 & 1986 \\
\hline \multirow[t]{4}{*}{ La Sierra } & 30 & Población ........ & 62.017 & 71.955 & 74.540 & 76.000 & 73.478 & 72.478 & 72.941 & 39.241 & 45.377 & 44.894 \\
\hline & & $\%$ Provincial ... & 24 & 23 & 23 & 21 & 20 & 20 & 18 & 15 & 11 & 10 \\
\hline & & Indice ............... & 100 & 116 & 120 & 122 & 119 & 117 & 117 & 95 & 73 & 72 \\
\hline & & Densidad ........ & 21 & 24 & 25 & 26 & 25 & 24 & 24 & 20 & 15 & 15 \\
\hline \multirow[t]{4}{*}{ El Andévalo } & 22 & Población ........ & 73.372 & 93.019 & 90.933 & 98.399 & 95.962 & 84.814 & 96.191 & 78.735 & 62.992 & 62.858 \\
\hline & & $\%$ Provincial ... & 28 & 30 & 28 & 28 & 26 & 23 & 24 & 20 & 15 & 14 \\
\hline & & Indice ............. & 100 & 127 & 124 & 134 & 131 & 116 & 131 & 107 & 36 & 86 \\
\hline & & Densidad $\ldots \ldots .$. & 22 & 28 & 28 & 30 & 29 & 26 & 29 & 24 & 19 & 19 \\
\hline \multirow[t]{4}{*}{ El Condado } & 15 & Población ........ & 54.235 & 58.574 & 63.672 & 65.255 & 68.299 & 74.061 & 76.298 & 73.171 & 69.429 & 76.045 \\
\hline & & $\%$ Provincial ... & 21 & 19 & 19 & 18 & 19 & 20 & 19 & 18 & 17 & 18 \\
\hline & & Indice $\ldots . . . . . . . .$. & 100 & 108 & 117 & 120 & 126 & 137 & 141 & 136 & 128 & 140 \\
\hline & & Densidad $\quad . . . . .$. & 23 & 25 & 27 & 28 & 29 & 32 & 33 & 31 & 30 & 33 \\
\hline \multirow[t]{4}{*}{ La Costa } & 5 & Población ........ & 24.176 & 30.303 & 37.461 & 40.459 & 42.418 & 42.895 & 48.639 & 54.083 & 63.900 & 66.106 \\
\hline & & $\%$ Provincial .... & 9 & 10 & 11 & 12 & 12 & 12 & 12 & 14 & 15 & 16 \\
\hline & & Densidad ........ & 42 & 52 & 65 & 70 & 73 & 73 & 84 & 94 & 110 & 114 \\
\hline & & Indice $\ldots \ldots \ldots \ldots$ & 100 & 125 & 155 & 167 & 175 & 177 & 201 & 224 & 263 & 273 \\
\hline Huelva y su & & Población ....... & 47.100 & 56.418 & 61.870 & 74.760 & 86.051 & 93.765 & 107.063 & 132.453 & 172.994 & 181.015 \\
\hline \multirow[t]{3}{*}{ area periurbana } & 7 & $\%$ Provincial ... & 18 & 18 & 19 & 21 & 23 & 25 & 27 & 33 & 42 & 42 \\
\hline & & Indice ............. & 100 & 120 & 131 & 159 & 183 & 199 & 227 & 281 & 367 & 384 \\
\hline & & Densidad ....... & 51 & 61 & 67 & 81 & 93 & 101 & 115 & 143 & 187 & 195 \\
\hline \multirow[t]{4}{*}{ Provincia } & 79 & Población ........ & 260.880 & 310.269 & 328.476 & 354.873 & 366.526 & 368.013 & 400.934 & 397.683 & 414.490 & 430.918 \\
\hline & & $\%$ Provincial ... & 100 & 100 & 100 & 100 & 100 & 100 & 100 & 100 & 100 & 100 \\
\hline & & Indice $\ldots . . . \ldots \ldots$ & 100 & 119 & 126 & 136 & 140 & 141 & 154 & 152 & 158 & 165 \\
\hline & & Densidad ....... & 25 & 31 & 33 & 35 & 36 & 37 & 40 & 39 & 41 & 42 \\
\hline
\end{tabular}

Fuente: Elaboración propia a partir de la Memoria de la Cámara de Comercio de Huelva, 1988. 


\section{CUADRO II}

EVOLUCION DEMOGRAFICA EN DIFERENTES INTERVALOS DE TIEMPO

\begin{tabular}{|c|c|c|c|c|c|c|c|c|c|c|c|c|}
\hline \multirow{2}{*}{ Municipios } & \multicolumn{4}{|c|}{$1900-1986$} & \multicolumn{4}{|c|}{$1970-1980$} & \multicolumn{4}{|c|}{$1980-1986$} \\
\hline & 1900 & 1986 & $\%$ Var. & $\mathrm{C}$ & 1970 & $\cdot 1980$ & $\%$ Var. & $\mathrm{C}$ & 1980 & 1986 & $\%$ Var. & $\mathrm{C}$ \\
\hline Aljaraque & 1.808 & 5.329 & +129 & M.P. & 3.627 & 4.458 & +23 & M.P. & 4,458 & 5.329 & +19.5 & M.P. \\
\hline EI Almendro .................... & 1.261 & 825 & -35.4 & M.R. & 1.238 & 852 & -31.2 & M.R. & 852 & 828 & -2.9 & E- \\
\hline Alosno ............................ & 8.187 & 4.770 & -41.8 & M.R. & 6.239 & 4.642 & -25.6 & M.R. & 4.642 & 4.770 & +2.7 & $\mathrm{E}+$ \\
\hline Ayamonte ........................ & 7.530 & 16.775 & +122 & P. & 13.099 & 16.216 & +23.8 & M.P. & 16.216 & 16.775 & +3.4 & E+ \\
\hline Cartaya ........................... & 5.552 & 9.698 & +75 & P. & 8.281 & 8.990 & +8.6 & P. & 8.990 & 9.698 & +7.8 & P. \\
\hline Gibraleón ...................... & 4.861 & 9.887 & +103 & P. & 8.602 & 8.996 & +4.6 & $\mathrm{E}+$ & 8.996 & 9.887 & +9.9 & P. \\
\hline El Granado ...................... & 799 & 633 & -20.8 & $\mathrm{R}$. & 1.911 & 1.320 & -30.9 & M.R. & 714 & 637 & -10.8 & R. \\
\hline Huelva & 21.359 & 135.427 & +534 & M.P. & 96.689 & 127.806 & +32.2 & M.P. & 127.806 & 135.427 & +5.9 & P. \\
\hline Isla Cristina & 5.969 & 14.954 & +150 & M.P. & 14.271 & 16.335 & +14.5 & P. & 16.335 & 14.954 & -8.5 & R. \\
\hline Lepe & 5.125 & 15.188 & +186 & M.P. & 11.826 & 13.669 & +15.6 & P. & 13.669 & 15.188 & $+11,1$ & P. \\
\hline Punta Umbría & - & - & - & M.P. & 6.606 & 8.490 & +28.5 & M,P. & 8.490 & 9.491 & +11.7 & P. \\
\hline S. Bartolomé de la Torre .. & 1.166 & 2.729 & +134 & M.P. & 2,313 & 2.433 & +5.1 & P. & 2.433 & 2.729 & +12.1 & P. \\
\hline Sanlúcar de Guadiana .... & 724 & 436 & -39.2 & M.R. & 645 & 449 & -30.4 & M.R. & 449 & 436 & -2.9 & $\mathrm{E}-$ \\
\hline San Silvestre de G. ....... & 848 & 718 & -15.4 & $\mathrm{R}$. & 960 & 806 & -16.1 & R. & 806 & 718 & -11 & $\mathrm{R}$. \\
\hline Villablanca ...................... & 1.711 & 1.900 & +11 & $\mathrm{R}$. & 1.989 & 1.753 & -11.9 & $\mathrm{R}$. & 1.753 & 1.900 & +8.3 & P. \\
\hline Villanueva de $\mathrm{C} . \quad \ldots \ldots \ldots . .$. & 2.537 & 2.457 & -3.2 & $\mathrm{R}$. & 2.808 & 2.431 & -13.4 & $\mathrm{R}$. & 2.431 & 2.457 & +1 & $\mathrm{E}+$ \\
\hline
\end{tabular}

C: Carácter; P: Progresivo; R: Regresivo; M.P.: Muy Progresivo; E.: Estacionario; M.R.: Muy Regresivo.

Fuente: Cámara de Comercio de Huelva, 1988. Elaboración propia. 
CUADRO III

DATOS GENERALES

\begin{tabular}{|c|c|c|c|c|c|}
\hline Municipio & $\begin{array}{c}\text { Superficie } \\
\left(\mathrm{Km}^{2}{ }^{2}\right)\end{array}$ & $\begin{array}{c}\text { Población } \\
1988 \text { (1) }\end{array}$ & $\begin{array}{l}\text { Densidad } \\
\text { H./Km. }\end{array}$ & $\begin{array}{l}\text { Población } \\
\text { casco princ. }\end{array}$ & $\begin{array}{l}\text { Altitud } \\
\text { (m.) }\end{array}$ \\
\hline Ayamonte & 145 & 17.278 & 119,1 & 14.208 & 18 \\
\hline Isla Cristina & 48 & 17.054 & 355,2 & 15.141 & 2 \\
\hline 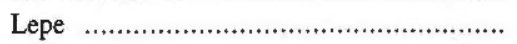 & 127 & 15.916 & 125,3 & Total & 6 \\
\hline Cartaya & 226 & 9.977 & 44,1 & 8.238 & 20 \\
\hline Punta Umbría & 36 & 9.950 & 276,3 & Total & 5 \\
\hline 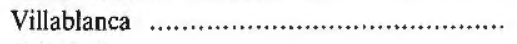 & 98 & 1.977 & 20,1 & Total & 96 \\
\hline 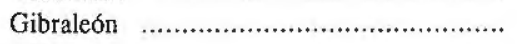 & 329 & 9.780 & 29,7 & 8.428 & 15 \\
\hline Aljaraque & 34 & 5.611 & 165,0 & 4.315 & 40 \\
\hline San Silvestre & 48 & 764 & 15,9 & Total & 158 \\
\hline San Bartolomé & 80 & 2.759 & 34,4 & Total & 100 \\
\hline 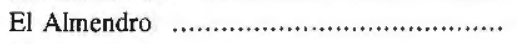 & 170 & 886 & 5,2 & Total & 232 \\
\hline Alosno & 201 & 5.001 & 24,8 & 2.416 & 172 \\
\hline Puebla de Guzmán ................................... & 320 & 3.376 & 10.5 & Total & 221 \\
\hline Sanlúcar de Guadiana . ............................... & 95 & 424 & 4,4 & 409 & 10 \\
\hline 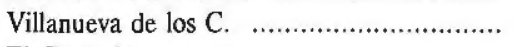 & 242 & 2.690 & 11,1 & 2.439 & 231 \\
\hline 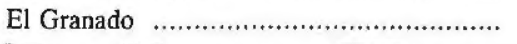 & 94 & 771 & 8,2 & Total & 139 \\
\hline
\end{tabular}

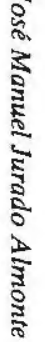

(1) Población de derecho. Rectificación del Padrón Municipal referido al 1 de Enero de 1988.

Fuente: Cámara de Comercio, Industria y Navegación de Huelva, 1988. Elaboración propia. 
CUADRO IV

DISTRIBUCION DE LAS PROPIEDADES SEGUN SUPERFICIE TOTAL

\begin{tabular}{|c|c|c|c|c|c|c|c|c|c|c|c|c|c|}
\hline \multirow{2}{*}{ Municipios } & \multirow{2}{*}{$\begin{array}{l}\text { Núm. total } \\
\text { explotac. }\end{array}$} & \multicolumn{2}{|c|}{$+0,1 a-5$} & \multicolumn{2}{|c|}{$+5 a-10$} & \multicolumn{2}{|c|}{$+10 a-20$} & \multicolumn{2}{|c|}{$+20 a-50$} & \multicolumn{2}{|c|}{$+50 a-100$} & \multicolumn{2}{|c|}{+100 Has. } \\
\hline & & Núm. & $\%$ & Núm. & $\%$ & Núm. & $\%$ & Núm. & $\%$ & Núm. & $\%$ & Núm. & $\%$ \\
\hline Ayamonte .................. & 315 & 114 & 36,0 & 69 & 21,5 & 53 & 16,5 & 45 & 14,5 & 14 & 4,5 & 22 & 7,0 \\
\hline Isla Cristina $\quad . . . . . . . . . . . .$. & 214 & 140 & 65,5 & 38 & 17,5 & 18 & 8,5 & 11 & 5,2 & 4 & 1,8 & 3 & 1,5 \\
\hline Lepe & 941 & 634 & 67,5 & 188 & 20,0 & 74 & 7,8 & 29 & 3,0 & 4 & 0,5 & 12 & 1,2 \\
\hline Cartaya ..................... & 853 & 521 & 61,0 & 167 & 19,5 & 102 & 12,0 & 35 & 4,0 & 37 & 2,0 & 11 & 1,5 \\
\hline Punta Umbría ........... & 9 & 5 & 55,5 & 1 & 11,1 & 1 & 11,1 & - & - & - & - & 2 & 22,3 \\
\hline Aljaraque $\quad$................... & 178 & 137 & 77,0 & 21 & 11,8 & 10 & 5,7 & 7 & 4,0 & - & - & 5 & 1,5 \\
\hline San Bartolomé $\quad$........... & 344 & 270 & 78,5 & 35 & 10,1 & 19 & 5,5 & 6 & 1,7 & 5 & 1,5 & 9 & 2,7 \\
\hline Gibraleón $\quad$..................... & 879 & 573 & 65,3 & 121 & 13,7 & 89 & 10,1 & 51 & 5,8 & 11 & 1,2 & 4 & 3,9 \\
\hline San Silvestre $\quad$.............. & 69 & 31 & 45,0 & 6 & 8,7 & 9 & 13,0 & 9 & 13,0 & 6 & 8,7 & 8 & 11,6 \\
\hline El Almendro ............... & 115 & 27 & 23,5 & 22 & 19,1 & 19 & 16,5 & 16 & 14,0 & 12 & 10,4 & 19 & 16,5 \\
\hline Alosno $\ldots \ldots \ldots \ldots \ldots \ldots$ & 118 & 27 & 22,9 & 28 & 23,7 & 21 & 17,8 & 15 & 12,7 & 6 & 5,1 & 21 & 17,8 \\
\hline Puebla de G. ............ & 123 & 22 & 17,9 & 15 & 12,2 & 8 & 6,5 & 17 & 13,8 & 8 & 6,5 & 53 & 43,1 \\
\hline Villanueva de los C. ... & 258 & 118 & 45,8 & 50 & 19,4 & 25 & 9,7 & 22 & 8,5 & 6 & 2,3 & 37 & 14,3 \\
\hline Sanlúcar de G. . ........... & 112 & 15 & 13,4 & 30 & 26,8 & 26 & 23,2 & 23 & 20,6 & 9 & 8,0 & 9 & 8,0 \\
\hline El Granado .................. & 93 & 58 & 62,3 & 11 & 11,8 & 9 & 9,8 & 4 & 4,3 & 2 & 2,1 & 9 & 9,7 \\
\hline PROVINCIA $\ldots \ldots \ldots \ldots$ & 25.555 & 16.477 & 64,5 & 3.442 & 13,5 & 2.158 & 8,5 & 1.607 & 6,3 & 681 & 2,6 & 1.190 & 4,6 \\
\hline
\end{tabular}

Fuente: Censo Agrario. Resultados Provinciales. Huelva, 1982. I.N.E.

Elaboración propia. 
CUADRO $\mathrm{V}$

DISTRIBUCION DE LOS TERRENOS (1987)

\begin{tabular}{|c|c|c|c|c|c|c|c|c|c|c|c|}
\hline \multirow{2}{*}{ Municipios } & \multicolumn{4}{|c|}{ Tierras de Cultivo } & \multicolumn{2}{|c|}{ Barbecho } & \multicolumn{2}{|c|}{ Forestal } & \multicolumn{2}{|c|}{ Otras Superficies } & \multirow{2}{*}{$\begin{array}{l}\text { Superficie } \\
\text { Total (has.) }\end{array}$} \\
\hline & Secano & Regadío & $\mathrm{A} \%(1)$ & $\mathrm{B} \%(2)$ & Has. & $\%$ & Has. & $\%$ & Has. & $\%$ & \\
\hline Ayamonte ....................... & 2.013 & 920 & 31,3 & 20,2 & 551 & 3,8 & 4.202 & 28,9 & 6.851 & 47,1 & 14.537 \\
\hline Isla Cristina .................. & 461 & 2.225 & 82,8 & 61,1 & - & - & 1.119 & 25,5 & 555 & 12,8 & 4.360 \\
\hline Lepe & 3.656 & 1.953 & 34,8 & 44,8 & 524 & 4,2 & 5.250 & 41,9 & 1.140 & 9,1 & 12.523 \\
\hline Cartaya & 4.024 & 1.063 & 20,9 & 24,0 & 255 & 1,3 & 15.648 & 74,0 & 145 & 0,7 & 21.135 \\
\hline Punta Umbría ............... & 136 & 154 & 53,1 & 9,5 & - & - & 1.092 & 35,7 & 1.676 & 54,8 & 3.058 \\
\hline Villablanca ....................... & 820 & 313 & 27,6 & 11,5 & 947 & 9,7 & 6.416 & 65,5 & 1.297 & 13,3 & 9.793 \\
\hline Gibraleón ...................... & 9.586 & 960 & 9,1 & 32,0 & 429 & 1,3 & 16.449 & 50,0 & 5.444 & 16,7 & 32.868 \\
\hline Aljaraque ......................... & 462 & 551 & 10,6 & 15,0 & 409 & 12,0 & 1.660 & 48,3 & 850 & 24,7 & 3.436 \\
\hline San Silvestre & 1.498 & 13 & 0,8 & 31,2 & 1.497 & 30,8 & 1.673 & 34,4 & 174 & 36 & 4.855 \\
\hline San Bartolomé . .............. & 1.008 & 189 & 15,7 & 15,6 & 264 & 3,5 & 6.003 & 79,3 & 123 & 1,6 & 7.647 \\
\hline 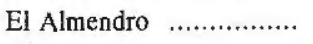 & 2.156 & 35 & 1,6 & 12,8 & 1.905 & 11,2 & 11.950 & 70,1 & 1.002 & 5,9 & 17.048 \\
\hline Alosno & 2.541 & - & - & 12,6 & 3.727 & 18,5 & 11.944 & 59,4 & 1.900 & 9,5 & 20.112 \\
\hline Puebla de Guzmán . ........ & 3.092 & 57 & 2,2 & 9,7 & 642 & 2,0 & 24.509 & 75,8 & 4.035 & 12,5 & 32.415 \\
\hline Villanueva de los C. ....... & 4.482 & 97 & 2,1 & 18,6 & 1.673 & 6,8 & 15.056 & 61,2 & 3.273 & 13,4 & 24.581 \\
\hline Sanlúcar de G. .............. & 708 & 30 & 4,0 & 7,7 & 1.295 & 13,5 & 5.193 & 54,3 & 2.337 & 24,5 & 9.563 \\
\hline El Granado ...................... & 671 & 7 & 1,0 & 7,2 & 678 & 7,2 & 6.337 & 67,4 & 1.711 & 18,2 & 9.404 \\
\hline
\end{tabular}

Fuente: Consejería de Agricultura y Pesca. Delegación Provincial de Huelva. Campaña Agrícola de 1987.

Elaboración propia.

(1) Superficie en regadío respecto al total de Tierras cultivables.

(2) Superficie cultivada respecto al total del municipio. 
CUADRO VI

ACTIVIDADES COMERCIAL E INDUSTRIAL

\begin{tabular}{|c|c|c|c|c|c|c|c|}
\hline Municipios & Economía & Comercio & $\begin{array}{l}\text { Licencias } \\
\text { industriales }\end{array}$ & $\begin{array}{l}\text { Licencias } \\
\text { comerciales }\end{array}$ & $\begin{array}{c}\text { Cuota } \\
\text { mercado }\end{array}$ & $\begin{array}{l}\text { Bancos- } \\
\text { cajas }\end{array}$ & $\begin{array}{l}\text { Consumo } \\
\text { miles } k w / h \text {. }\end{array}$ \\
\hline Ayamonte ........................... & Muy diversificada & Muy desarrollado & 303 & 1.038 & 37 & 12 & 14.665 \\
\hline Isla Cristina & Muy diversificada & Especializado & 163 & 1.139 & 36 & 11 & 22.764 \\
\hline Lepe & Diversificada & Especializado & 171 & 1.054 & 30 & 12 & 18.413 \\
\hline Cartaya ............................... & Diversificada & Especializado & 112 & 636 & 19 & 8 & 8.940 \\
\hline Punta Umbría ...................... & Muy diversificada & Muy desarrollado & 114 & 837 & 21 & 8 & 16.781 \\
\hline Villablanca ............................ & Agropecuaria & Mínimo & 17 & 97 & 2 & 2 & 2.740 \\
\hline Gibraleón .............................. & Intermedia & Algo especializado & 97 & 482 & 17 & 7 & 10.736 \\
\hline Aljaraque & Intermedia & Especializado & 44 & 285 & 6 & 3 & 6.190 \\
\hline San Silvestre & Simple & Mínimo & 2 & 35 & - & 2 & 1.310 \\
\hline San Bartolomé & Intermedia & Mínimo & 34 & 139 & 3 & 2 & 3.208 \\
\hline El Almendro .......................... & Agropecuaria & Mínimo & 6 & 47 & - & 1 & 2.210 \\
\hline 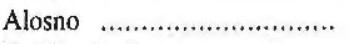 & Intemedia & Algo especializado & 34 & 280 & 7 & 2 & 4.503 \\
\hline 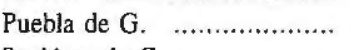 & Agro-minera & Algo especializado & 27 & 171 & 5 & 2 & 1.570 \\
\hline Sanlúcar de G. ..................... & Simple & Mínimo & 3 & 20 & - & 1 & 805 \\
\hline Villanueva de los C. ............ & Agropecuaria & Mínimo & 37 & 176 & 5 & 4 & 2.243 \\
\hline El Granado ........................... & Simple & Mínimo & 4 & 37 & - & 2 & 2.243 \\
\hline
\end{tabular}

Econornía simple: Totalmente agraria de tipo familiar con alto porcentaje de autoabastecimiento y escasos intercambios exteriores.

Fuente: Cámara de Comercio, Industria y Navegación de Huelva, 1987/88.

Elaboración propia. 


\section{CUADRO VII}

TRANSPORTES Y COMUNICACIONES. 1988

\begin{tabular}{|c|c|c|c|c|c|}
\hline Mnnicipios & $\begin{array}{l}\text { Núm. } \\
\text { turismos }\end{array}$ & $\begin{array}{l}\text { Núm. } \\
\text { camiones }\end{array}$ & $\begin{array}{l}\text { Núm. vehíc. } \\
\text { x } 1.000 \text { htes. }\end{array}$ & $\begin{array}{c}\text { Núm. } \\
\text { teléfonos }\end{array}$ & $\begin{array}{l}\text { Núm. teléfs. } \\
\times 1.000 \text { htes. }\end{array}$ \\
\hline Ayamonte .................................. & 2.092 & 171 & 130 & 1.910 & 110 \\
\hline 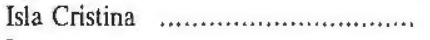 & 2.145 & 146 & 134 & 2.411 & 141 \\
\hline Lepe & 3.100 & 154 & 204 & 2.527 & 158 \\
\hline Cartaya & 1.382 & 170 & 155 & 1.151 & 115 \\
\hline Punta Umbría & 1.306 & 144 & 145 & 3.015 & 302 \\
\hline Villablanca & 280 & 28 & 155 & 172 & 87 \\
\hline 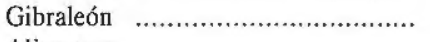 & 1.750 & 88 & 188 & 1.145 & 117 \\
\hline 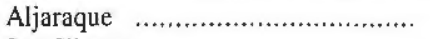 & 1.047 & 69 & 199 & 889 & 158 \\
\hline San Silvestre & 116 & 1 & 153 & 69 & 90 \\
\hline San Bartolomé . ........................... & 409 & 25 & 157 & 344 & 124 \\
\hline El Almendro & 98 & 3 & 114 & 61 & 68 \\
\hline Alosno & 610 & 29 & 127 & 585 & 117 \\
\hline Puebla de Guzmán ......................... & 479 & 11 & 145 & 238 & 70 \\
\hline Sanlúcar de Guadiana & 50 & 8 & 136 & 63 & 148 \\
\hline Villanueva de los C. ..................., & 520 & 57 & 214 & 288 & 107 \\
\hline El Granado ...................................... & 92 & - & 119 & 55 & 71 \\
\hline
\end{tabular}

Fuente: Cámara de Comercio de Huelva y Consejería de Fomento y Trabajo de la Junta de Andalucía, 1988. Elaboración propia.

\section{CUADRO VIII}

INDICES DE ACCESIBILIDAD; RODEO Y FRECUENCIA DE TRANSPORTES CON HUELVA-CAPITAL

\begin{tabular}{|c|c|c|c|c|c|c|c|}
\hline Municipios & $\begin{array}{l}\text { Servicios } \\
\text { líneas aut. }\end{array}$ & $\begin{array}{l}\text { Tiempo } \\
\text { real (1) }\end{array}$ & $\begin{array}{l}\text { Tiempo } \\
\text { óptimo }\end{array}$ & $\begin{array}{c}\text { Distancia } \\
\text { real (kms.) }\end{array}$ & $\begin{array}{c}\text { Distancia } \\
\text { óptima }\end{array}$ & $\begin{array}{l}\% \text { Indice } \\
\text { accesib. }\end{array}$ & $\begin{array}{l}\% \text { Indice } \\
\text { rodeo }\end{array}$ \\
\hline 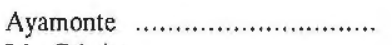 & 16 & 48 & 25 & 52 & 41 & 52,0 & 78,8 \\
\hline Isla Cristina $\quad$........................... & 9 & 45 & 21 & 47 & 34 & 46,6 & 72,3 \\
\hline 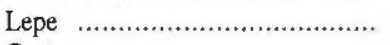 & 17 & 27 & 13 & 32 & 22 & 48,1 & 68,7 \\
\hline 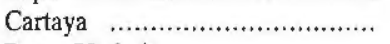 & 12 & 20 & 11 & 25 & 18 & 48,1 & 72,0 \\
\hline Punta Umbría ....................... & 16 & 19 & 5 & 20 & 9 & 26,3 & 45,0 \\
\hline 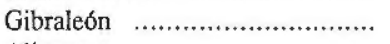 & 4 & 10 & 8 & 14 & 13 & 80,0 & 92,8 \\
\hline 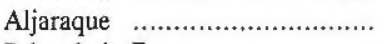 & 26 & 6 & 4 & 7 & 6 & 66,6 & 85,7 \\
\hline 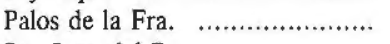 & 16 & 12 & 4 & 13 & 6 & 66,6 & 85,7 \\
\hline San Juan del P. ....................... & 25 & 8 & 7 & 15 & 12 & 87,5 & 80,0 \\
\hline 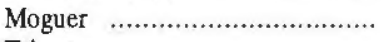 & 9 & 16 & 6 & 20 & 10 & 37,5 & 50,0 \\
\hline 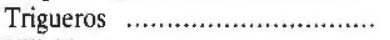 & 9 & 13 & 10 & 20 & 17 & 76,9 & 85,0 \\
\hline Villablanca & 2 & 50 & 20 & 47 & 34 & 40,0 & 72,3 \\
\hline San Silvestre $\quad$........................... & 2 & 62 & 23 & 59 & 38 & 37,0 & 64,4 \\
\hline San Bartolomé ....................... & 10 & 25 & 15 & 30 & 25 & 60,0 & 83,3 \\
\hline El Almendro & 3 & 51 & 24 & 47 & 40 & 47,0 & 85,1 \\
\hline Alosno & 2 & 46 & 21 & 44 & 35 & 45,6 & 79,5 \\
\hline Puebla de Guzmán ................... & 5 & 64 & 28 & 63 & 47 & 43,7 & 74,6 \\
\hline Sanlúcar de Guadiana .............. & 1 & 75 & 31 & 70 & 51 & 41,3 & 72,9 \\
\hline Villanueva de los C. ................ & 4 & 49 & 23 & 47 & 39 & 46,9 & 82,9 \\
\hline El Granado ............................ & 1 & 60 & 30 & 56 & 50 & 50,0 & 89,2 \\
\hline
\end{tabular}

(1) Se ha considerado el recorrido a una velocidad media de $100 \mathrm{kms} . \mathrm{h}$. El tiempo viene registrado en minutos. Fuente: Elaboración propia a partir de consultas a la empresa Damas, S.A. (1989). 


\section{CUADRO IX}

MOVILIDAD TRABAJO-RESIDENCIA. AREAS DE INFLUENCIA

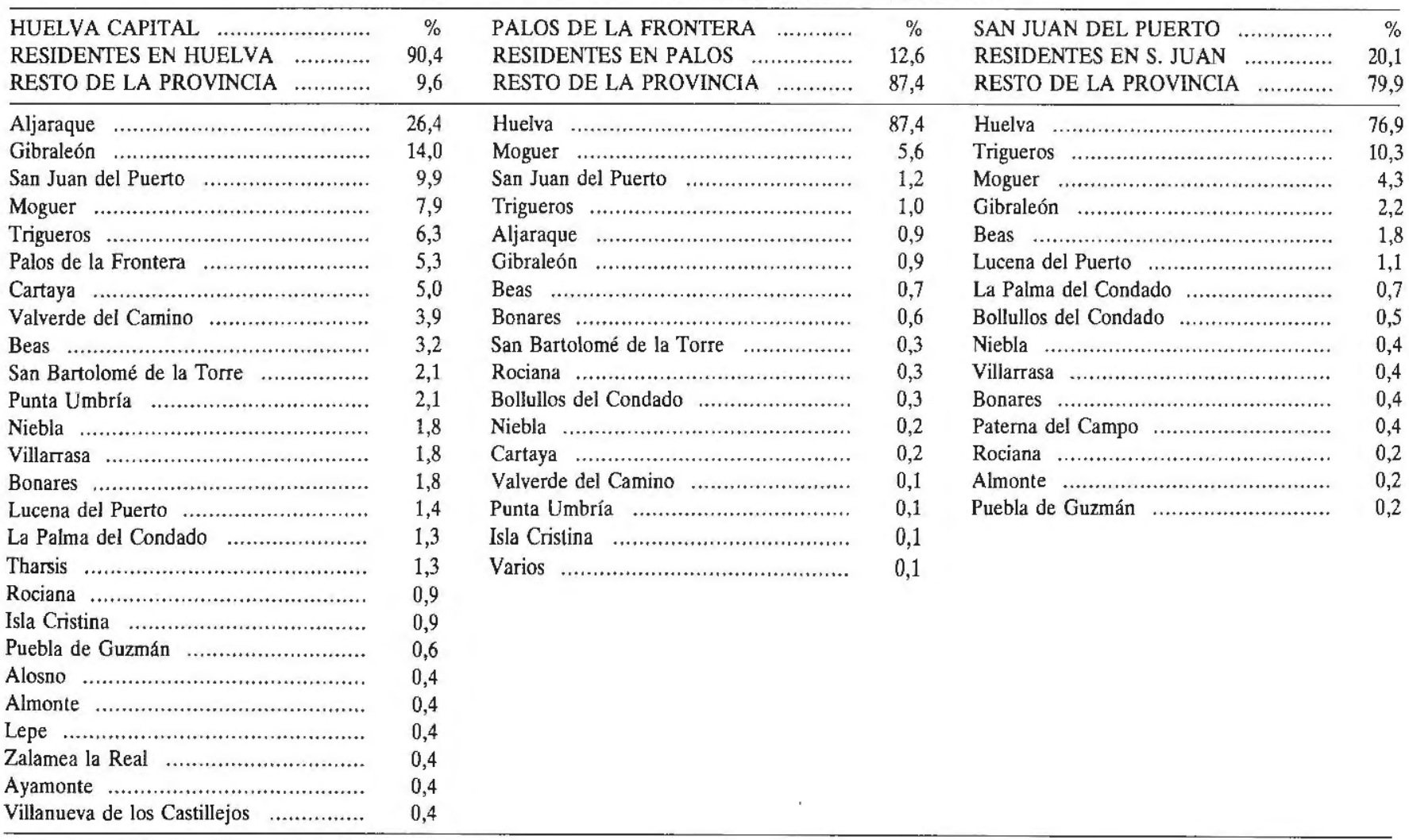


CUADRO X

EVALUACION DE LAS TASAS DE EQUIPAMIENTO. 1987/88

\begin{tabular}{|c|c|c|c|c|}
\hline Municipio & LC & $\mathrm{PO}$ & TE & $\mathrm{CM}$ \\
\hline 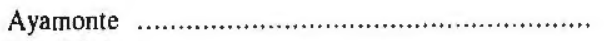 & 1.038 & 16.775 & 6,18 & 37 \\
\hline 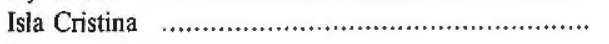 & 1.139 & 14.954 & 7,61 & 36 \\
\hline Lepe & 1.054 & 15.188 & 6,94 & 30 \\
\hline Cartaya & 748 & 9.698 & 7,71 & 19 \\
\hline Punta Umbría & 951 & 9.491 & 10,02 & 21 \\
\hline Aljaraque & 329 & 5.329 & 6,17 & 6 \\
\hline 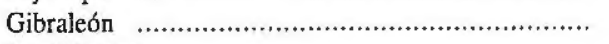 & 579 & 9.887 & 5,85 & 17 \\
\hline San Silvestre & 35 & 718 & 4,87 & - \\
\hline San Bartolomé & 139 & 2.729 & 5,09 & 3 \\
\hline 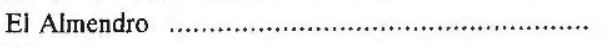 & 47 & 828 & 5,67 & - \\
\hline Alosno & 280 & 4.770 & 5,87 & 7 \\
\hline Puebla de G. & 171 & 3.171 & 5,39 & 5 \\
\hline 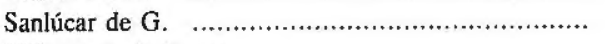 & 20 & 436 & 4,58 & - \\
\hline Villanueva de los $\mathrm{C}$. & 176 & 2.456 & 7,16 & 5 \\
\hline El Granado & 37 & 633 & 6,84 & - \\
\hline HUELVA-CAPITAL & 8.605 & 135.427 & 6,35 & 320 \\
\hline
\end{tabular}

LC: Licencias Comerciales.

PO: Población de hecho en 1986.

TE: Tasa de Equipamiento: licencias comerciales por 100 habitantes.

CM:Cuota de Mercado.

Fuente: Cámara de Comercio, Industria y Navegación de Huelva, 1988. Elaboración propia. 


\section{CUADRO XI}

NIVEL DE EQUIPAMIENTO Y DESPLAZAMIENTOS: SERVICIOS VARIADOS

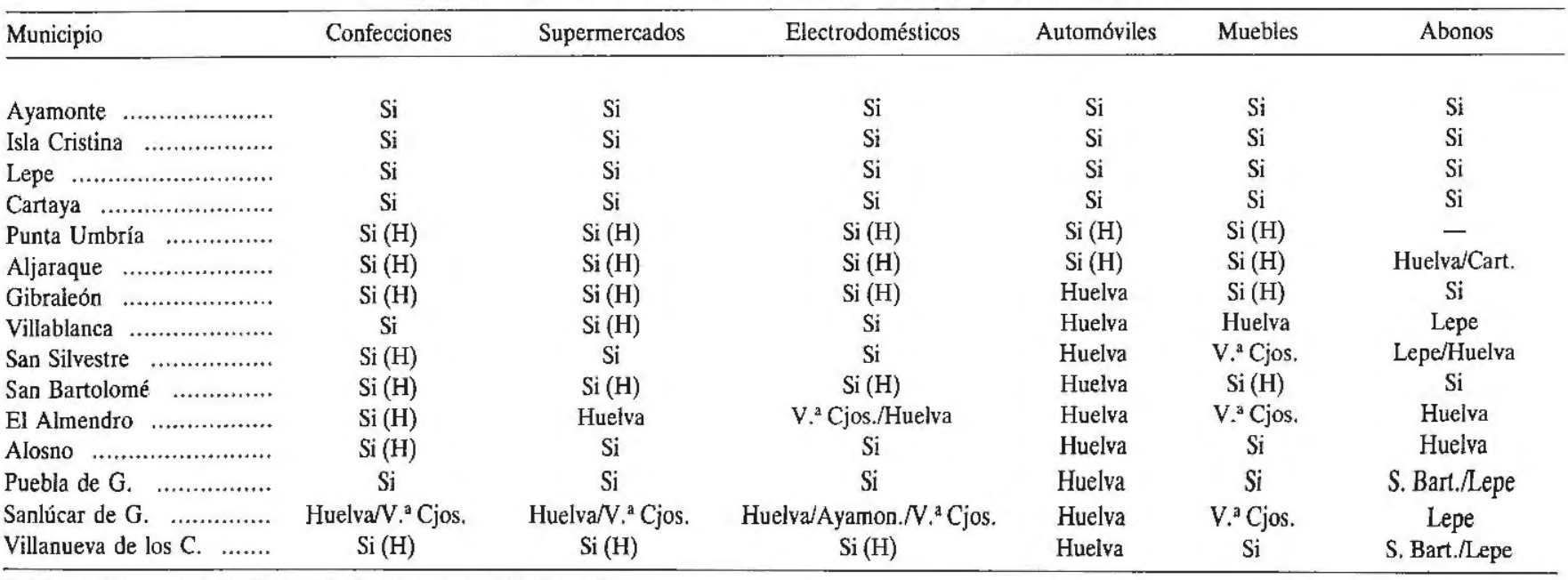

Si: Poseen dicho servicio, usado mayoritariamente por la población residente.

$\mathrm{Si}(\mathrm{H})$ : Poseen dicho servicio pero tienen como altemativa paralela su adquisición y desplazaniento a Huelva-capital.

$V^{2}{ }^{2}$ Castillejos/Huelva: Municipios de destino para la adquisición de servicios por su ausencia (en orden preferente).

Fuente: Encuestas en los respectivos Ayuntamientos (1989).

Elaboración propia. 
CUADRO XII

NIVEL DE EQUIPAMIENTO Y DESPLAZAMIENTOS. OTROS SERVICIOS COMERCIALES

\begin{tabular}{|c|c|c|c|c|c|c|c|}
\hline Municipio & Gestoría & Autoescuela & Tintorería & Fotografía & Optica & Sastrería & Sondeos \\
\hline Ayamonte ......................... & $\mathrm{Si}$ & $\mathrm{Si}$ & $\mathrm{Si}$ & $\mathrm{Si}$ & $\mathrm{Si}$ & $\mathrm{Si}$ & $\mathrm{Si}$ \\
\hline Isla Cristina . ................... & $\mathrm{Si}$ & $\mathrm{Si}$ & $\mathrm{Si}$ & $\mathrm{Si}$ & $\mathrm{Si}$ & $\mathrm{Si}$ & $\mathrm{Si}$ \\
\hline 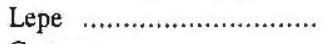 & $\mathrm{Si}$ & $\mathrm{Si}$ & $\mathrm{Si}$ & $\mathrm{Si}$ & $\mathrm{Si}$ & $\mathrm{Si}$ & $\mathrm{Si}$ \\
\hline 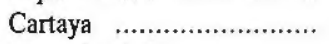 & $\mathrm{Si}$ & $\mathrm{Si}$ & $\mathrm{Si}$ & $\mathrm{Si}$ & $\mathrm{Si}$ & Huelva & Lepe \\
\hline Punta Umbría ................ & $\mathrm{Si}(\mathrm{H})$ & $\mathrm{Si}$ & Huelva & $\mathrm{Si}(\mathrm{H})$ & $\mathrm{Si}(\mathrm{H})$ & Huelva & Lepe \\
\hline Aljaraque ...................... & $\mathrm{Si}(\mathrm{H})$ & Huelva & Huelva & $\mathrm{Si}(\mathrm{H})$ & Huelva & Hnelva & Lepe \\
\hline Gibraleón $\quad \ldots \ldots \ldots \ldots \ldots \ldots \ldots . . . . . . .$. & $\mathrm{Si}(\mathrm{H})$ & $\mathrm{Si}$ & Huelva & $\mathrm{Si}$ & Huelva & Huelva & $\mathrm{Si}$ \\
\hline Villablanca $\ldots \ldots \ldots \ldots \ldots \ldots$ & $\mathrm{Si}(\mathrm{H})$ & Ayamonte & Huelva & Ayamonte & Ayamonte & Huelva/Lepe & Lepe \\
\hline San Silvestre & Ayamonte & Ayamonte & Huelva & Huelva & Huelva & Huelva & Lepe \\
\hline San Bartolomé ................. & Huelva & $\mathrm{Si}(\mathrm{H})$ & Huelva & Huelva & Huelva & Huelva & Lepe/Gibraleón \\
\hline El Almendro ................... & Huelva & Huelva & Huelva & Huelva & Huelva & Huelva & Huelva \\
\hline 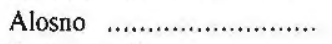 & Huelva & $\mathrm{Si}$ & Huelva & $\mathrm{Si}$ & Huelva & Huelva & Huelva/Lepe \\
\hline 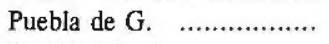 & Huelva & Huelva & Huelva & $\mathrm{Si}$ & Huelva & Huelva & Valverde \\
\hline Sanlúcar de G. ................ & Huelva/V. ${ }^{\mathrm{a}}$ Cjos. & Huelva & Huelva & Huelva & Huelva & Huelva & Lepe/Huelva \\
\hline Villanueva de los C. ........ & $\mathrm{Si}(\mathrm{H})$ & $\mathrm{Si}$ & Huelva & Huelva/Ayamon. & Huelva & Huelva & $\mathrm{Si}$ \\
\hline
\end{tabular}

Fuente: Encuestas en los respectivos Ayuntamientos, 1989

Elaboración propia. 
CUADRO XII

NIVEL DE EQUIPAMIENTO Y DESPLAZAMIENTOS. SERVICIOS PROFESIONALES

\begin{tabular}{|c|c|c|c|c|c|c|}
\hline Municipio & Dentista & Veterinario & Abogado & Notario & Arquitecto & Juez $1 .{ }^{\mathrm{a}}$ Inst, \\
\hline Ayamonte & $\mathrm{Si}$ & $\mathrm{Si}$ & $\mathrm{Si}$ & $\mathrm{Si}$ & $\mathrm{Si}$ & $\mathrm{Si}$ \\
\hline Isla Cristina & $\mathrm{Si}$ & $\mathrm{Si}$ & $\mathrm{Si}$ & $\mathrm{Si}$ & $\mathrm{Si}$ & Ayamonte \\
\hline Lepe & $\mathrm{Si}$ & $\mathrm{Si}$ & $\mathrm{Si}$ & $\mathrm{Si}$ & $\mathrm{Si}$ & Ayamonte \\
\hline Cartaya & $\mathrm{Si}$ & $\mathrm{Si}$ & $\mathrm{Si}$ & $\mathrm{Si}$ & $\mathrm{Si}$ & Huelva \\
\hline Punta Umbría & $\mathrm{Si}$ & Cartaya & $\mathrm{Si}$ & $\mathrm{Si}$ & $\mathrm{Si}$ & Huelva \\
\hline Aljaraque & Huelva & $\mathrm{Si}$ & Huelva & Hủelva & $\mathrm{Si}$ & Huelva \\
\hline Gibraleón & $\mathrm{Si}(\mathrm{H})$ & $\mathrm{Si}$ & $\mathrm{Si}(\mathrm{H})$ & $\mathrm{Si}$ & Si & Huelva \\
\hline 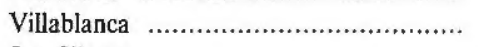 & Ayamonte & $\mathrm{Si}$ & Ayamon./Lepe & Ayamon./Lepe & Huelva & Ayamonte \\
\hline San Silvestre & Ayamonte & $\mathrm{Si}$ & Ayamonte & Ayamonte & Huelva & Ayamonte \\
\hline San Bartolomé . ................................... & Huelva & $\mathrm{Si}$ & Huelva & Huelva/Gibral. & Huelva & Huelva \\
\hline 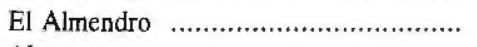 & Huelva & $\mathrm{Si}$ & Huelva & Ayamon./Huelva & Huelva & Ayamonte \\
\hline Alosno & $\mathrm{Si}(\mathrm{H})$ & $\mathrm{Si}$ & $\mathrm{Si}$ & Valverde & Huelva & Valverde \\
\hline Puebla de G. & Huelva & $\mathrm{Si}$ & Huelva/Valverde & $\mathrm{Si}$ & Huelva & Valverde \\
\hline 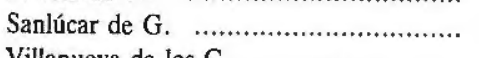 & Ayamonte & V. ${ }^{\text {a }}$ Cjos. & V. ${ }^{a}$ Cjos. & Ayamon./Lepe & Ayamon./Lepe & Ayamonte \\
\hline 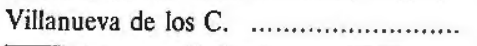 & Huelva & $\mathrm{Si}$ & Huelva/Ayamon. & Ayamonte & $\mathrm{Si}$ & Valverde \\
\hline
\end{tabular}


CUADRO XIV

NIVEL DE SERVICIOS Y DESPLAZAMIENTOS. EQUIPAMIENTOS URBANOS

\begin{tabular}{|c|c|c|c|c|c|c|}
\hline Municipio & Inst. B.U.P. & Centro F.P. & Biblioteca & Asilo & Matadero Ind. & Piscinas \\
\hline Ayamonte & $\mathrm{Si}$ & $\mathrm{Si}$ & $\mathrm{Si}$ & $\mathrm{Si}$ & No & No \\
\hline 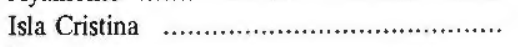 & $\mathrm{Si}$ & Lepe & Si & No & No & No \\
\hline Lepe & Cartaya & $\mathrm{Si}$ & $\mathrm{Si}$ & $\mathrm{Si}$ & $\mathrm{Si}$ & No \\
\hline Cartaya & $\mathrm{Si}$ & Lepe & $\mathrm{Si}$ & $\mathrm{Si}$ & $\mathrm{Si}$ & No \\
\hline Punta Umbría & $\mathrm{Si}$ & $\mathrm{Si}$ & $\mathrm{Si}$ & No & No & $\mathrm{Si}$ \\
\hline Aljaraque & Huelva & Huelva & $\mathrm{Si}$ & Huelva & Huelva & No \\
\hline Gibraleón & $\mathrm{Si}(\mathrm{H})$ & Huelva & $\mathrm{Si}$ & $\mathrm{Si}$ & $\mathrm{Si}$ & No \\
\hline 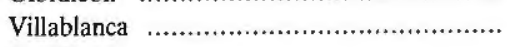 & Ayamon./Huelva & Lepe & No & Ayamonte & No & No \\
\hline San Silvestre & Ayamonte & Lepe & No & Ayamonte & No & No \\
\hline San Bartolomé & Huelva/Gibral. & Huelva/Alosno & Huelva & Huelva & No & No \\
\hline 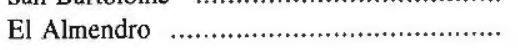 & Puebla de G. & Alosno & No & Ayamon./Calañas & No & No \\
\hline Alosno & Puebla de G. & $\mathrm{Si}$ & $\mathrm{Si}$ & $\mathrm{Si}$ & $\mathrm{Si}$ & $\mathrm{Si}$ \\
\hline 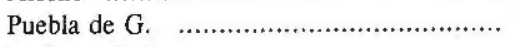 & $\mathrm{Si}$ & Alosno/Valverde & $\mathrm{Si}$ & Huelva/Gibraleón & No & No \\
\hline 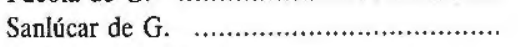 & Puebla de G. & Alosno & No & No & No & No \\
\hline 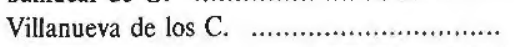 & Puebla de G. & Alosno & No & No & $\mathrm{Si}$ & No \\
\hline
\end{tabular}

Fuente: Encuestas en los respectivos Ayuntamientos, 1989

Elaboración propia. 
CUADRO XV

MOVILIDAD LABORAL. DESPLAZAMIENTOS PERIODICOS.

\begin{tabular}{|c|c|c|c|}
\hline Municipio & A & $\mathrm{B}$ & $\mathrm{C}$ \\
\hline 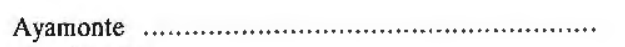 & - & No & - \\
\hline Isla Cristina & - & No & - \\
\hline 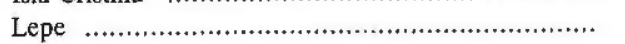 & - & No & - \\
\hline 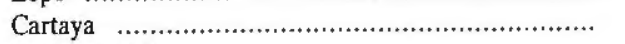 & Huelva & No & Pesca/Industria \\
\hline Punta Umbría & Huelva/Cartaya & No & Agric./Pesca/Servicios \\
\hline Aljaraque & Huelva/Cartaya/P. Umbría & $\mathrm{Si}$ & Servicios/Industria \\
\hline Gibraleón & Huelva & $\mathrm{Si}$ & Indust./Constr./Servicios \\
\hline Villablanca & Lepe/I.Cristina/Huelva & Relativo & Agricultura/Construcción \\
\hline San Silvestre & I.Cristina/Ayamonte & $\mathrm{Si}$ & Agricultura \\
\hline San Bartolomé & Huelva & Relativo & Construcción/Industria \\
\hline El Almendro & V. ${ }^{\text {a }}$ Cjos./Cartaya/Lepe & $\mathrm{Si}$ & Agricultura/Construcción \\
\hline Alosno & Huelva/La Costa & Relativo & Agricultura/Construcción \\
\hline Puebla de Guzmán & Huelva/Lepe/Cartaya & Relativo & Agric./Servicios/Industria \\
\hline 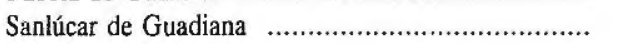 & La Costa & $\mathrm{Si}$ & Agricultura \\
\hline Villanueva de los $\mathrm{C}$. & Huelva/Cartaya/Lepe & Realtivo & Agricultura/Construcción \\
\hline
\end{tabular}




\section{FUENTES}

Entrevistas-encuestas a los Ayuntamientos del ámbito suroccidental de Huelva.

Delegación Provincial en Huelva de la Consejería de Agricultura y Pesca.

Dirección provincial del I.A.R.A. de Huelva.

Dirección General de Turismo. Consejería de Economía y Fomento.

Centro de Estudios Territoriales y Urbanos. Consejería de Obras Públicas y Transportes.

\section{BIBLIOGRAFIA}

AVILA FERNANDEZ, D.: Los recursos humanos y su distribución espacial. Estudio demográfico de Lepe. Ayuntamiento de Lepe, Noviembre, 1985.

BIELZA DE ORY, V.: «La problemática de las regiones funcionales», en La Región y la Geografía española, A.G.E., Valladolid, 1980, pp. 53-64.

CAMARA DE COMERCIO DE HUELVA: Memorias anuales, años 1985, 1986/87 y 1987/88.

CANO GARCIA, G.: Aproximación al Análisis Geográfico Regional, S.P.U., Sevilla, 1985.

CEOTMA: Divisiones territoriales en España, M.O.P.U., Madrid, 1982.

EPYPSA: Avance de Ordenación Litoral. Ayamonte, Isla Cristina, Lepe, Punta Umbría e Isla Saltés, Consejería de Obras Públicas y Transportes, Junta de Andalucía, 1986.

FERIA TORIBIO, J.M.: Análisis locacional de la provincia de Huelva, I.D.R., Sevilla, 1986.

FOURNEAU, F.: La provincia de Huelva y los problemas de Desarrollo Regional, Diput. Provincial de Huelva, 1983.

HUElVA: Informe de la Costa. Consejo Económico Provincial Sindical, Huelva, 1969.

I.N.E.: Censo Agrario. Resultados de la provincia de Huelva, Tomo III, 1982.

JORDA, R.: Dinámica y distribución reciente de la población andaluza, I.D.R., Univ. de Sevilla, 1986.

JUNTA DE ANDALUCIA: Caracterización socio-económica de las comarcas andaluzas, Consejería de Política Territorial, 1986.

JUNTA DE ANDALUCIA: Evaluación ecológica de los recursos naturales de Andalucía, Agencia de Medio Ambiente, 1989.

JUNTA DE ANDAlUCIA: Plan Especial de Protección de Medio Físico de la Provincia de Huelva, 1985.

JUNTA DE ANDALUCIA: Sistema de ciudades en Andalucía, Consejería de Política Territorial, Sevilla, 1986.

MARCHENA, M. y MARQUEZ, J.: «Procesos y expectativas de la Agricultura y el Turismo en el Litoral de Huelva", Actas IV Coloquio Nacional de Geografía Agraria, A.G.E., Canarias, I987, Tomo I, pp. 120-138.

MARQUEZ DOMINGUEZ, J.: "El comercio en Andalucía», Geografía de Andalucía, (Dir. Cano, G.), Vol. VI, pp. 13-80, 1988. 
MARQUEZ DOMINGUEZ, J.: La nueva agricultura onubense, I.D.R., Universidad de Sevilla, 1987. MONTEAGUDO, J.: Comarcalización y organización del territorio en la provincia de Huelva, Cánara Oficial de Comercio, Industria y Navegación de Huelva, 1986.

MOPU: La Comarca en la Ordenación Territorial, Coloquio sobre Ordenación Territorial, 1986.

PEZZI, M.: La comarcalización de Andalucía, Universidad de Granada, 1982.

VILA VALENTI, J.: «El concepto de Región», La Región y la Geografía española, A.G.E., Valladolid, 1980, pp. 13-34. 